\title{
Convergence Characteristics of Nonlinear Vortex-Lattice Methods for Configuration Aerodynamics
}

Arnan Seginer, Z. Rusak, and E. Wasserstrom

June 1983

\section{LIBRARY COPY}

AllG 11983

LANGLEY RESEARCH CENTER

LIBRARY, NASA

HAMPTON, VIRGINIA 
NASA Technical Memorandum 84371

\section{Convergence Characteristics of Nonlinear Vortex-Lattice Methods for Configuration Aerodynamics}

Arnan Seginer, Ames Research Center, Moffett Field, California

Z. Rusak and E. Wasserstrom, Technion-Israel Institute of Technology, Haifa, Israel

\section{N/S/}

National Aeronautics and

Space Administration

Ames Research Center

Moffett Field, California 94035 
CONVERGENCE CHARACTERISTICS OF NONLINEAR VORTEX-LATTTCEE METHODS FOR CONFIGURATION AERODYNAMICS

Arnan Seginer*

NASA Ames Research Center, Moffett Fleld, Calif 94035

Z. Rusakt and E. Wasserstrom

Technion-Israel Inst1tute of Technology, Haifa, Israel

\section{Abstract}

Nonlinear panel methods have no proof for the existence and unfqueness of their solutions. The convergence characteristics of an iterative, nonIfnear vortex-lattlce method are, therefore, carefully investigated. The effects of several parameters, including 1) the surface-paneling method, 2) the integration method of the trajectorles of the wake vortices, 3) vortex-grid refinement, and 4) the initial conditions for the first iteration on the computed aerodynamic coefficlents and on the flow fleld detafls are presented. The convergence of the 1terative-solution procedure is usually rapid. The solution converges with grid refinement to a constant value, but the final value is not unique and varies with the wing surface-paneling and wake-discretization methods within some range in the vicinity of the experimental result.

\section{Nomenclature}

$\mathrm{AR}$

= aspect ratio

$\left.a_{k 1}, b_{k j},\right\}=$ influence coefficlents defined in Eq. (4) $c_{k}$

$\mathrm{a}, \mathrm{b}=$ semt-axes of the ellipsoid in Fig. 3

b $\quad=$ wing span

$\mathrm{c}_{\mathrm{b}} \quad=$ span bending-moment coefficient

$\mathrm{C}_{\mathrm{D}_{\mathrm{i}}} \quad=$ induced-drag coefficient $=\mathrm{D}_{1} / \mathrm{qS}$

$\mathrm{C}_{\mathrm{L}} \quad=$ lift coefficient $=\mathrm{L} / \mathrm{qS}$

C. $\quad=$ section $11 \mathrm{ft}$ coefficient

$\mathrm{C}_{\mathrm{M}} \quad=$ pitching-moment coefficient $=\mathrm{M} / \mathrm{qSC}$ ma

$\mathrm{C}_{\mathrm{NOR}}=$ normal-force coefficlent $=$ NOR $/ \mathrm{qS}$

$\mathrm{C}_{\mathrm{p}} \quad=$ pressure coefficient $=\left(\mathrm{p}-\mathrm{p}_{\infty}\right) / \mathrm{q}$

$\therefore C_{p} \quad=$ local load coefficient on the wing

c = alrfoll-section local chord

$c_{\text {ma }}=$ mean aerodynamic chord

*NRC Senfor Research Associate, Aerodynamic Research Branch. Associate Professor, on leave from the Technion-Israel Institute of Technology. Member AIAA.

Graduate student, Department of Aeronautical Engineering.

†Associate Professor, Department of Aeronautical Englneering. Member AIAA.

\begin{tabular}{|c|c|}
\hline$e_{r}$ & $=$ root chord \\
\hline 1 & $=$ Induced drag \\
\hline$\vec{F}$ & $=$ vector of singulärity intensities \\
\hline L & $=11 \mathrm{ft}$ \\
\hline e & $=1$ length of rolled-up wake \\
\hline $\mathrm{M}$ & $=$ pitching moment \\
\hline NOR & $=$ normal force \\
\hline s & $=$ number of source panels on the body \\
\hline $\mathrm{s}$ & $=$ number of vortex panels on the wings \\
\hline & $\begin{array}{l}\text { unlt vector normal to the surface, point- } \\
\text { ing into the flow }\end{array}$ \\
\hline & $=$ spanwise number of vortex panels \\
\hline$c$ & $=$ chordwise number of vortex panels \\
\hline & $=$ static pressure \\
\hline & $=$ free-stream dynamic pressure \\
\hline 1 & $=$ strength of source panel number ( 1 ) \\
\hline & $=$ underrelaxation coefficient (Eq. (8)) \\
\hline $\mathbf{S}$ & $=$ wing area (wetted surface) \\
\hline$u, v, w$ & $=$ perturbation velocity components \\
\hline$i_{\infty}$ & $=$ free-stream velocity vector \\
\hline n & $\begin{aligned}= & \text { vector of the free-stream velocity com- } \\
& \text { ponents that are normal to the panels. }\end{aligned}$ \\
\hline$x, y, z$ & $\begin{array}{l}\text { Cartesian coordinates in the downstream, } \\
\text { right-wing, and upward directions, } \\
\text { respectively. }\end{array}$ \\
\hline$\therefore \mathrm{x}_{\mathrm{w}}, \therefore \mathrm{x}_{\mathrm{p}}$ & $\begin{array}{l}=\text { length scales in the wake and on the } \\
\text { wing panels, respectively }\end{array}$ \\
\hline 8 & $=$ angle of attack \\
\hline & $=$ strength of bound vortex number $(j)$ \\
\hline & $=$ free-vortex shedding angle \\
\hline$\phi$ & $=$ perturbation-velocity potential \\
\hline$\omega$ & $\begin{aligned}= & \text { weighting parameter in second-order } \\
& \text { integration (Eq. (8)) }\end{aligned}$ \\
\hline
\end{tabular}


Vortex-lattice methods (VLM) have been used to compute the lift of wings for the last 35 years. They were an extension of Prandt1's lifting-line theory to 7 ifting owrfaces. Falkner's works, ${ }^{1-3}$ probably the earliest in this area, laid the foundations for the method, using distributed vorticity. Discretization into a vortex lattice was introduced by Young and Harper, ${ }^{4}$ and many computer programs, solving for the unknown vortex intensities, were developed during the following years (e.g., Ref. 5) and applied to various problems.

The VLM 1s basically one of many panel methods that are more accurately described as surface singularity methods. Generally speaking, panel methods distribute panels of singularities (sources, doublets, or vortices) on the surfaces of bodies that are immersed in a flow. The strengths of the singular elements are determined by satisfying the tangency boundary condition on the body surfaces, and once these are known the influence of the body on any point in the flow fleld can be computed. Hunt ${ }^{6}$ shows that the VLM is equivalent to a piecewise-constant doublet distribution and classifies it as a zero-order panel method.

As such, and as long as compatible boundary conditions are used, ${ }^{6}$ a unique solution exists for the vortex distribution. Th1s can be proven, however, only for the so-called "1lnear" case, when the geometry of the wake that is generated by the vorticity distribution is known ab initio. ${ }^{6}$ The classic example of a linear case is the streamwise-ortented planar wake of the finite wing in Prandt's liftingline theory. In practical cases the real wake is distorted after being shed and rolls up about 1ts streamw1se edges. Its geometry is part of the unknown flow field. The "nonlinear" panel methods are composed of complicated iterative techniques that "relax" the wake to its rolled-up, force-free shape and account for the two-way interaction of the lifting surfaces with their wakes by correcting the singularity distribution with every new shape of the wake.

Nonlinear VLMs were developed in the last decade and were used extensively to compute the vortex lift of slender wings at high angles of attack. ${ }^{7-18}$ These methods were extended to 11fting slender bodies 19,20 and to high-angle-of-attack aerodynamics of multiple-wing body configurations of missiles and fighter alrcraft. ${ }^{21}$ Each step of the nonlinear iterative process in these methods is, in itself, a linear solution. It recomputes the intensitles of the vortices for every corrected wake shape using a prescribed wake geometry and has, therefore, a unique solution. However, there is no proof of the existence of a unique solution for the nonlinear procedure. This means that even when the iterative solution converges, one has no assurance of its uniqueness. This lack of proof of uniqueness motivated the present authors to conduct a careful study of the convergence characteristics of the method and its sensitivity to various geometrical and numerical parameters during the development of their nonlinear vortex-lattice computer program for wing-body configurations. ${ }^{21}$ Th1s paper describes the method briefly and presents its convergence characteristics vis-à-vis various parameters such as the vortex-panel size and shape, or the length of the free-vortex discrete segments.
The method described in Ref. 21 was developed to compute the flow fields over winged flight vehicles at high angles of attack, and to predict their aerodynamlc coefficlents. The results of these computations for typical missile and fighteralrcraft conflgurations are presented there, and the full detal1s of the numerical schemes are given in Ref. 22. Following is a brief description of the mathematical model used in this method.

Assuming a steady, incompressible, inviscid; and Irrotational flow (except for discrete vortices), the disturbance flow fleld of a vehicle flying in a untform flow can be described by the Laplace equation:

$$
\nabla^{2} \phi=0
$$

If the flow is subsonic and small perturbations are assumed, the following discussion will also apply when the Prandt1-Glauert equation is substituted for Eq. (1).

The solution to the Laplace equation is determined by the tangency boundary condition

$$
\overline{\partial \phi / \partial \mathrm{n}}+\overline{\mathrm{v}}_{\infty} \cdot \overline{\mathrm{n}}=0
$$

that has to be satisfled everywhere on the conflguration surfaces, and by the requirement that the perturbations vanish at infinite distances from the configuration. In the case of lifting configurations, their wakes are considered part of the conflguration surface, ${ }^{6}$ and the tangency boundary condition (Eq. (2)) has to be satisfied on them as we11. This means that no pressure or velocity jump can exist across the wake or, in other words, that the wake must follow the local streamlines. This unknown location of part of the computationa1domain boundary, which has to be determined iteratively, makes the problem nonlinear, although the Laplace equation is linear.

When Green's third 1dentity is used, the problem of finding the volume distribution of a potential function is replaced by the problem of finding a surface distribution of singular elements (sources or doublets) that satisfies the boundary conditions. In the present method, the body, which would be nonlifting in potential flow, is modeled by a distribution of source panels only. The liftIng surfaces are assumed to be of zero thickness and are modeled by a vortex lattice, where the discrete vortices are equivalent to a piecewise constant doublet distribution. Discrete free line vortices are shed from all the free edges of the lifting surfaces, and their trafectorles in the wake are determined by integration of the local streamline equations

$$
\mathrm{dy} / \mathrm{dx}=\mathrm{v} /\left(\mathrm{V}_{\infty}+\mathrm{u}\right) ; \mathrm{d} z / d \mathrm{x}=\mathrm{w} /\left(\mathrm{v}_{\infty}+\mathrm{u}\right)
$$

from the shedding point into the far wake. At some predetermined distance downstream, the free vortex IInes are replaced by semi-infinite straight lines in the direction of $\bar{V}_{\infty}$.

Since any singularity distribution identically satisfies the Laplace equation (Eq. (1)) and the boundary condition at infinity, the simultaneous satisfaction of Eqs. (2) and (3) should generate the correct solution. Equation (2) must, however, be 
satisfled on the wake also, the position of which, beling part of the solution, is still unknown. Therefore, the solution procedure has to be Iterative or have an impulsive start. In the 1terative technique used here, the intensities of the singularities are determined by satisfying the boundary condition (Eq. (2)) on the surfaces of the configuration and on an assumed wake shape. A new wake shape is determined by integrating Eq. (3), using the velocities induced by the previously computed singularities, and is used to recompute the intensities of the singularities. This process is repeated until the solution converges.

\section{Method of Solution}

The body flow fleld is simulated by a conventional source-pane1 method. ${ }^{23}$ The body surface is approximated by a number $\left(\mathrm{N}_{\mathrm{S}}\right)$ of trapezoldal panels carrying a plecewise-constant source distribution of unknown strength $q_{1}$. The collocation point at which the boundary condition (Eq. (2)) is satisfied is at the center of the panel area. A typical paneling scheme of the body is shown in Fig. 1 .

The flow field generated by the lifting surfaces is described by a nonlinear VLM. ${ }^{18}$ The zerothickness lifting surfaces are divided into a number $\left(\mathrm{N}_{\mathrm{v}}\right)$ of vortex panels. These are mostly rectangular. However, the triangular panels of Rom and Zorea are used along the edges of swept:wings (F1g. 1). It will be shown later that this choice of the RomZorea paneling had a first-order effect on the computational results. A discrete horseshoe vortex of unknown strength $\Gamma_{j}$ is bound to the 1/4-chord line of each panel. The tralling arms of the vortex are also bound to the surface along the panel streamwise demarkation Ines untfl they reach one of the wing edges. From there they are shed as free vortices (FIg. 1). The collocation points on the vortex panels are located at the Intersection of the longitudinal median of the panel with 1 ts $3 / 4$-chord 1ine.

A complete geometric definition of the problem also needs a specification of the wake shape. If better information is not avallable, the tralling vortices can be assumed to be semi-infinite stralght lines leaving the wing edges at some predetermined angle above the wing surface: Past experience ${ }^{21}$ has shown that any angle between the chordwise and the streamwise directions would do, but the cholce of half the angle of attack is common.

With the geometry defined, one has only to satisfy the tangency boundary condition (Eq. 2) simultaneously at all the collocation points. This results in a system of $\left(\mathrm{N}_{\mathrm{S}}+\mathrm{N}_{\mathrm{v}}\right)$ linear algebraic equations for the unknown intensities of the sources and vortices

$$
\begin{array}{r}
\sum_{i=1}^{N_{s}} a_{k f 1} q_{1}+\sum_{j=1}^{N_{v}} b_{k j} \Gamma_{j}+c_{k}=0 \\
\quad\left(k=1,2, \ldots . . N_{s}+N_{v}\right)
\end{array}
$$

where $c_{k}=\left(\vec{V}_{\infty} \cdot \vec{n}\right)_{k}$ is the component of the freestream velocity that is normal to the panel number (k) at its collocation point, and $a_{k i}$ and $b_{k j}$ are the influence coefficients of the source panel ( 1 ) and the vortex $(j)$, respectively, on the collocation point of panel $(\mathrm{k})$. An influence coeffictent is defined as the normal component $(\partial \phi / \partial n)_{k}$ of the velocity that is 1nduced on panel $(k)$ by a singular potential element of unit strength. The influence of a vortex includes the influence of tts tralling free arms, requiring the predetermination of their spatial location. Detalled formulae for the influence coefficients are given in Ref. 22, and are not needed here for a discussion of the convergence characteristics.

Rewritten in matrix form, Eq. (4) becomes

$$
[B W] \bar{F}+\bar{V}_{n}=0
$$

where [BW] is an $\left(\mathrm{N}_{S}+\mathrm{N}_{\mathrm{V}}\right)$ square matrix of the influence coefficients, $\bar{F}$ is the vector of singularity intensities

$$
\bar{F}=\left\{\begin{array}{l}
a_{i} \\
i_{j}
\end{array}\right\}
$$

and $\bar{V}_{n}$ is the vector $\bar{v}_{n}=\left\{c_{k}\right\}$. The matrix $[B W]$ can be partitioned into

$$
[\mathrm{BW}]=\left[\begin{array}{ll}
\mathrm{BOB} & \text { WOl } \\
\mathrm{BOW} & \text { WOh }
\end{array}\right]
$$

where $B O B$ and $B O W$ represent the Influence coefficients of the body sources on the collocation points of the body panels and wing panels, respectively, and $W O B$ and WOW represent the influence coeff1clents of the wing vortices (including the tralling free vort1ces) on the body panels and wing panels, respectively. $B O B$ and $B O W$ are computed only once because of the fixed geometry of the surface panels, but WOB and WOW have to be recomputed whenever the wake shape changes.

Equation (7) is solved for the intensities of the singular elements $\left(q_{i}, \Gamma_{j}\right)$. This is a linear problem and has, in principle, a unique solution. With these intensities known, the velocities induced by them on any point in the flow fleld can be computed and Eq. (3) can be Integrated for the trajectories of the free vortices. The trajectories define a new wake shape that is used to recompute the singularity intensities from $\mathrm{Eq}$. (7). The calculation cycle (Fig. 2) is relterated unt1l the wake solution converges to a constant shape (within a given tolerance).

Once the computation is converged, the load distribution on the lifting surfaces is computed from the Kutta-Joukowoski theorem, and the pressure distribution on the body is obtained from the Bernoulli equation. These distributions are integrated to compute the lift, Induced-drag, and pitching-moment coefficients. Detalls of all the calculations are given in Ref. 22. Only those necessary for the study of the convergence characteristics of the method will be discussed here.

\section{Validation of the Computer Code}

The objective of this investigation was to study the convergence characteristics of the nonlinear computation scheme for which there is no proof of the existence and uniqueness of the solution. First, the computer code had to be validated in its linear mode to ensure its proper functioning when a unique solution existed by comparing the 
. :

results with other exact solutions or with proven numerica1 results.

The source-panel body-simulation program was validated by comparing its results with the exact, analytically calculated, zero-Incidence pressure distribution over an elilpsold. Figure 3 deplcts the relative error $\left(\Delta C_{p} / C_{p}\right)$ in the pressure coefficient as calculated by the present method. A mesh refinement (to 240 pane1s). resulted in a highly accurate solution except for a maximum error of $4 \%$ in the stagnation region, where a higher panel density would be needed to account for the large local gradlents. Accurate results (F1g. 4) were obtalned on an ogtve-cylinder at $\alpha=6^{\circ}$ because of the smaller gradients. They are validated by comparison with the commonly used Woodward method. ${ }^{24}$

The vortex-1atice wing-simulation part of the program was validated first by comparison with analytical results for the chordwise circulation distribution on a two-dimensional flat-plate alrfoll (at $\alpha=4^{\circ}$ ) and for the spanwise circulation distribution over PrandtI's lifting-line representation of a finfte wing. The agreement in both cases was good. Figure 5 shows the relative error in the results for the flat-plate alrfoil and the effects. of mesh refinement on these results (the results for the lifting line are not shown here). The computed circulation is within $0.25 \%$ of the theoretical value over most of the chord, even with only 10 vortex panels. The error increases near the leading edge because of 1 ts strong singularity and near the trailing edge where the denominator in the relative error goes to zero. It is interesting to note that the influence of mesh refinement (above $\mathrm{N}_{\mathrm{v}}=10$ ) on the Integrals of the circulation (the section lift and pitching-moment coefficients) is insignificant ${ }^{22}$ (not shown).

Further validation of the VLM code was obtained on the delta wing, depleted in Fig. 6, with and without the presence of the body. Chordwise and spanwise load distributions at several locations on the wing, obtained with the Rom-Zorea paneling ${ }^{8}$ (F1g. 6a), were compared ${ }^{22}$ with the results of the classic VLM trapezoldal paneling (Fig. 6b) and with results of a trapezoidal paneling (Fig. 6c) with a piecewise constant doublet distribution. (Jacobs, A., Private communication, IAIFLo computer code, Courtesy of the Israel Alrcraft Industry. Ben-Gurion Int'1. Alrport, Lod, Israel, 1982.) One representative chordwise load distribution on the wing at the $20.5 \%$ span station $\left(\alpha=6^{\circ}\right)$ 1s shown in Fig. 7. These data were obtained in the presence of the body that was modeled in all three programs by the same geometrical source-panel distribution. The continuity of the vorticity distribution at the wing-body intersection line was obtained by the continuation of the wing-root panels through the body ${ }^{22}$ (Fig. 6). The good agreement between the three methods in Fig. 7 and in Ref. 22 validated the IInear mode of the present program.

\section{Parameters Influencing Convergence}

The solution to the nonlinear problem is obtained by an iterative procedure that is terminated when convergence is reached. One of the following three convergence criterla can be chosen arbitrarily according to the user's needs. The aerodynamic coefficients of the configuration are the least sensitive and converge first. A later convergence is obtalned when the surface-pressure distribution is used as the convergence indicator. The most sensitive convergence test is the shape of the wake, wh1ch may continue to change long after the other parameters have converged. A typical convergence process of the aerodynamfc coefficients of a cructform missile configuration is shown in Fig. 8 for the wings in a "plus" or in an $x$ configuration. The convergence is fast. Only four iterations are needed for the aerodynamic ccefficients to converge, in spite of the large error in the results of the first iteration. The wake in these computations converged after seven 1terations. Agreement of the converged pitching-moment coefficlent with the data of R. Arleli (unpublished experimental results, Technion-IIT, Haifa, Israel, 1982) is good, whereas the normal-force coefficient 1s within $5 \%$ of the measured value. This difference will be discussed later.

Since the changing shape of the wake determines the solution of the nonlinear problem, it is safe to assume that the parameters of the wake and of its numerical treatment may influence the convergence rate, or even determine if convergence is possible at all. These parameters may also influence the converged results if the solution is not uni que.

The wake parameters that may be involved and have been studied here are

1) The integration method of the free-vortex trajectorles (Eq. (3))

2) The cutoff distance for the interaction of two close free vortices or for the interaction of a free vortex with a very close source panel

3) The paneling method and its effect on the free-vortex trajectorles

4) The length of the integrated rolled-up wake (the distance to the effective far wake)

5) An Initial guess of the shedding angle of the free vortices

6) The grid refinement in the wake and on the solid surfaces

All three convergence criteria were considered. A convergence criterion of one count in the lift coefficlent would suffice for engineering purposes. A more demanding convergence criterion would be a maximum change in the local pressure of $0.01 \mathrm{p}_{\infty}$ Finally, changes between 1terations in freevortex trajectorles should be limited to a maximum of one-tenth of the smallest vortex-panel dimension. The criterion $\Delta C_{I} \leq 0.0001$ covered all of the above and was used as a single convergence criterion.

\section{Free-Vortex Trajectory Integration}

Equation (3) can be integrated by several methods. The general second-order integration of $\mathrm{dy} / \mathrm{dx}=\mathrm{f}(\mathrm{x}, \mathrm{y})$ (the two-dimensional example was chosen for the sake of simplicity) would be

$$
\begin{aligned}
y_{1+1}= & y_{1}+R(\Delta x)\left\{(1-\omega) f\left(x_{1}, y_{1}\right)+\omega f\left[x_{1}+\frac{\Delta x}{2 \omega}, y_{1}\right.\right. \\
& \left.\left.+\frac{\Delta x}{2 \omega} f\left(x_{1}, y_{1}\right)\right]\right\}+0\left(\Delta x^{3}\right)
\end{aligned}
$$


where $R$ is an underrelaxation coefficient $(0<R \leq 1)$. The usual second-order integration uses $\omega=0.5$. W1th $\omega=0$, Eq. (8) is reduced to the simple, first-order Euler integration method, and $\omega=1$ gives an Improved Euler scheme. In addition to these three methods, a second-order Runge-Kutta predictor-corrector was used.

The simple Euler method was the least time consuming per 1teration, whereas the Runge-Kutta method was, of course, the most time consuming. The differences between the converged solutions were too small to justify the increased computation costs (see also Refs. 8, 14, 20, 22). Therefore, the first-order Euler scheme is recommended. The convergence rate of this scheme in a scalar computation can be accelerated when the most recently updated wake shape is used to compute the induced velocities in Eq. (3) for the updating of the next grid point. This, however, prevents vectorlzation on a vector computer and the more efficient method has to be determined by trial and error.

The Euler integration can be performed along a single vortex line out to the far wake, or can be marched downstream across the wake, correcting the first segments of all free vortices first, then the second segments, etc. No difference was found between the converged results of the two methods.

An underrelaxation $(R<1)$ can be used to prevent the solution from diverging because of large fluctuations in the wake shape. Underrelaxation was usually not necessary in the present work, but Almosnino ${ }^{25}$ reports that strong underrelaxation $(0.3 \leq R \leq 0.5)$ had to be used for convergence of wakes shed from bodies.

In conclusion, the integration method of the wake shape does not affect the uniqueness of the solution once it converges.

\section{Cutoff Distances for a Strong Interaction}

When a dense vortex lattice is used to improve the solution (discussed later), free vortices are apt to pass close to each other, at least during the iterations for the wake shape. The very high velocities induced at a close proximity of two potential vortices may cause the solution to diverge. This problem can be eliminated by preventing the induced velocity from increasing above a certain level. Three methods have been introduced in the past to achieve this purpose $e^{14}$ : a "viscous core" (solid-body rotation) can be added to every vortex, two vortices can be combined into one when they are too close, or a constant induced velocity can be used instead. All three methods depend on an arbitrary specification of a lower bound on the distance separating two vortices. This distance is often called the "cutoff distance." Reference 20 presents an interesting argument for the choice of a cutoff distance that depends on the parameters of the vortex model and on the free-stream velocity. However, 1t. Is based on empirical consideration and has no physical justification.

In a wing-body Interaction solved by the present method, ${ }^{21}$ free vortices. that are shed from the lifting surfaces may pass too close to a bound vortex on another surface, or to a source-panel on the body surface. As in the previously discussed case, the resulting strong interaction may have a catastrophic influence on the iterative computation. A cutoff distance, simflar to that above, must also be applied here. Without a sound theoretical basis for the specification of the, cutoff distance, one has to rely on trial and error. Results of experimentation with the cutoff distance ${ }^{22}$ indicate that it should be bounded from below by one-tenth of the smaller of the surface-panel dimensions, and from above by one-quarter of the same dimension. Above the upper bound the interaction is not fully accounted for. Below the lower bound the Induced velocities are too strong and the solution may diverge. The wake roll-up in both cases is incorrect. This means, however, that the solution is no longer unique and now depends on this cutoff distance.

\section{Effects of Paneling Scheme}

The paneling scheme (FIg. 6, trapezoidal, rectangular, and triangular) did not affect the results of the Iinear solutions (e.g., F1g. 7) which were in good agreement with experimental data obtained at low angles of attack. ${ }^{5}$ This was found not to be true in the nonlinear case. Whereas all the methods that accounted for leading-edge separation could predict the lift coefficient fairly well (F1g. 9), the present method underpredicted the pitching moment of Ref. 26 (F1g. 10) because the pressure distribution (both in the chordwise and spanwise directions) was incorrect (F1g. 11). The inboard pressures were too high and the outboard pressures were too low. The leading-edge suction peak was always too close to the leading edge when the Rom-Zorea paneling was used. $8,14,18$ It is interesting to note here that, in spite of the locally incorrect pressures, any line integral of the pressures gave good results. A chordwise integral resulted in a good prediction of the local. section 1 ift coefficient, and a spanwise integral gave a good approximation of the local contribution to the wing-root bending moment ${ }^{22}$ (Fig. 12). The center of rotation and the center of gravity of the free vortices, as computed in the cross-flow plane (F1g. 13), did not agree with the experimental data of Ref. 27.

These problems did not plague the delta-wing solutions of Ref. 15. A careful comparison of these solutions with the present ones showed that the vortices in the trlangular panels along the leading edge (Fig. 1) in the present method were significantly weaker than those of Ref. 15. This could only be the result of the paneling method.

In the present method the bound vortex lies completely within the triangular panel along its $1 / 4$-chord line, with the collocation point in the middle of the $3 / 4$-chord line (Fig. 14). This results in a bound vortex that is longer than those of the rectangular panels and results in a relatively shorter distance to the collocation point, both results contributing to a lower vortex intensity $\left(\Gamma_{j}\right)$ in the solution of Eq. (4). These length differences become more pronounced as the leadingedge sweep angle is increased. In the paneling of Ref. 15 (Fig. 14), the bound vortex started at the inboard 1/4-chord of the triangular panel and continued out of the wing and into the flow, normal to the leading edge, ending on the chordwise line drawn through the outboard corner of the panel (Fig. 14). Thus, it was of about the same length as the vortices in the rectangular panels with approximately the same distance to the collocation point. The shorter vortex length resulted inia 
higher vortex strength than in the present method and better pressure distributions. ${ }^{15}$ When the wing aspect rat 10 is increased and the leading-edge sweep angle is decreased, the paneling methad of Ref. 15 increases the distance to the collocation point and overpredicts the strength of the leadingedge vortex. It seems that maintaining a constant ratio of the length of the bound vortex to its distance to the collocation point would achleve the best results. This has been pointed out recently by Gordon and Rom. ${ }^{28}$ In their calculations, the trlangular panel was pract1cally replaced by a standard rectangular panel and the computed results agreed well with experimental data. However, the physical meaning of-extending the leading-edge bound vortices into the outer flow field is not clear. In fact, the mathematical model of the delta wings of Refs, 15 and 28 resembles a wing with sawteeth, which must certainly have different aerodynamic characteristics than delta wings.

In conclusion, the results of the nonlinear mathematical model are not unique. since they depend on the vortex model and on its geometrical relation to the paneling scheme.

\section{The Length of the Rolled-up Wake}

The detalled computation of the shape of the rolled-up wake (the integration of Eq. 3) is performed from the vortex shedding points to a prescribed distance $\left(l_{\mathrm{w}}\right)$ that is assumed to be the beginning of the "far wake." Further downstream the vortices are continued to infinity as straight lines. This practice saves computation time, since longer rolled-up wakes use more computer time and memory volume.

The effect of the prescribed distance to the far wake or the computational results was small. The variation of the lift and pitching-moment coefficients of two delta wings (aspect ratios of 2.0 and 1.0 at $\alpha=20^{\circ}$ ) with $\left(l_{w}\right)$ is shown in Fig. 15. A rolled-up; wake length of half the mean aerodynamic chord was sufficient for the convergence of the aerodynamic coefficients.

\section{Inttial Shedding Angle}

An Inttial guess of the wake shape has to be used in the first iteration cycle of the computation for the determination of the influence coefficients of the free vortices in Eq. (5). Unless a specific wake shape from a previous solution is used, the simplest and easiest choice is of a linear wake (1.e., semi-infinfte straight lines that leave the shedding points) deflected up or down from the freestream direction at an angle $(\mu)$. Angles between $\mu=0^{\circ}$ (aligned with $\bar{v}_{\infty}$ ) and $\mu=\alpha$ (aligned with the chord) are used. A common choice is $\mu=\alpha / 2$.

Investigation of the influence of the initial shedding angle $(\mu)$ value on the convergence characteristics of the method showed that $\mu$ (vithin the above limits) had no effect on the converged yalues of the aerodynamic coefficlents (FIg. 16), and had but little effect on the convergence rate (Fig. 1Ja), even when the wake was initlally deflected upward, too far away from its final position (Fig. 17b).

\section{Grid Refinement}

In a findte-difference solution of a differential equation, a mesh refinement should, in princ1- ple, converge to the solution of the differential. equation itself, whereas in VLMs there is no proof that 1t should, The tangency boundary condition 1 s satisfiled at the collocation points only, while everywhere else the fluld "leaks" through the surface. This leak will not be eliminated by grid refinement. St111, the character and trends of the varlation of the solution with vortex-grid refinement is Indicative of the unfqueness of the solution.

The nonlinear VLM has two supposedly independent length scales. One is the length $\left(\Delta x_{w}\right)$ of the free-vortex segments in the wake that is used in the integration of the wake shape (Eq. (3)). The other is the length (or chord) of the vortex panel $\left(\Delta x_{p}\right)$. A reduction in $\left(\Delta x_{w}\right)$ should result in a smoother vortex 11ne that is closer to the exact solution of the streamilne equations. The effect of the reduction in the segment length on the $1 \mathrm{ft}$ coefficlents of two delta wings (AR of 1.0 and 2.0 at $\alpha=20^{\circ}$ ) is shown in Fig. 18 for several constant vortex-panel sizes. When the length of the vortex panel $\Delta x_{p}=c_{r} / a_{c}$ is kept constant, the ratio of panel length to vortex-segment length $c_{r} /\left(n_{c} \cdot \Delta x_{w}\right)$ goes to Infinity as $\Delta x_{w}$ goes to zero.

The lift coefficient does exhibit a convergent character when the segment length is reduced. However, when $\Delta x_{w}$ becomes much smaller than the panel length (typlcaliy less than one-quarter of $\Delta x_{p}$ ) the iteration process becomes unstable and dfverges. Very long wake segments (typically more than five times longer than the pane1) usually destablilize the computation. The differences between the solutions with different segment lengths can be large

(F1g. 18). The experimental lift coefficients for the same wings are shown for comparison in Fig. 18 .

Furthermore, F1g. 18 shows a very'strong effect of the panel size on the lift coefficient. This effect is investigated in Fig. 19, where the lift coefficlents of the same two wings are plotted as a function of the total number of vortex panels on pne-half of the wing (one-half was sufficient for a symetric solution). This is done for several constant wake segment lengths. The experimental lift coefficlents are also shown. The lift coefficient again shows a tendency to exponentially approach a constant value when the grid is refined. This final value depends, however, on the length of the free-vortex segment.

To isolate the dependence of the results on the two length scales, the previous results are replotted in Fig. 19 as the varfations of the lift coefficient, the induced drag coefficient, and the location of the center of pressure with the increasIng number of vortex panels for several constant ratios of the free-vortex segment length to panel 1ength. By using this ratio as a parameter, the grid refinement applies simultaneously to both characteristic lengths. The lift and drag coefficients show a tendency to reach their final values at or above 171 vortex panels (obtained by a division of the root-chord and semi-span into 18 equal parts). The final value of the lift coefficient depends on the wake-segment-to-panel-1ength ratio. A simflar behavior observed by Gordon and Rom, 28 who used a different paneling scheme, indicates that this effect of the length rat10 is not a result of the paneling method. 
A comparison of the computed $11 \mathrm{ft}$ coefficients with the experimental data for three delta wings (Fig. 19) offers an approximate engineering formula for the cholce of a length ratio that, when used for delta wings in the present method, results in convergence (resulting from grid refinement) to Ilft coefficlents that are in fair agreement with the experimental data (for the aspect-ratio range tested here from $\mathrm{AR}=0.5$ to $\mathrm{AR}=2.0$ ). A ratio of $\left(\Delta x_{w}\right) /\left(\Delta x_{p}\right) \cong\left(9+A R^{2}\right)^{1 / 2} / A R$ (or the simplified $\left.\Delta x_{w} / \Delta x_{p} \cong 3 / A R\right)$ is recommended, although no reasonable explanation can be offered for this correlation.

It is interesting to note that the correct location of the center of pressure (F1g. 14) is obtained even with a coarse vortex lattice and does not depend on the length-scale ratio. Apparently, the variation of the load distribution over the wing with both grid refinement and length-scale ratio is self-similar, so that the lift and pitching moment change simultaneously without moving the center of pressure.

Another indication of convergence with grid refinement is the ratio $C_{D_{1}} /\left(C_{L} \tan \alpha\right)$, where $C_{D_{1}}$ is the induced drag coefficient calculated by integration of the forces that are exerted on the bound vortices by the induced cross-flow velocities. The coefficient $C_{D_{i}}$ should, in principle, be equal to $\mathrm{C}_{\mathrm{L}} \tan \alpha$ and the ratio $\mathrm{C}_{\mathrm{D}_{1}} /\left(\mathrm{C}_{\mathrm{L}} \tan \alpha\right)$ should converge to 1.0. Grid refinement does indeed lead to convergence (FIg. 14), but only to a value of about 0.9 . Note that this ratio is absolutely independent of the length-scale ratio..

\section{Conclusions}

The convergence characterlstics of the nonlinear VLM have been thoroughly investigated. It is shown in this paper that the iterative solution procedure usually converges. Divergence can be prevented by a proper choice of a cutoff distance for the interaction of close singularities and by an underrelaxation of the iterative correction of the wake shape.

The computed results are independent of the specific integration method of the trajectories of the free vortices in the wake. The far-wake approximation can be applied at the relatively short distance of half the mean aerodynamic chord behind the wing trafling edge with no detrimental effects on the computed results. The converged values of the aerodynamic coefficients are independent of the initial guess for the vortex shedding angle.

Although grid refinement leads to convergence, the solution is not unique in this respect. The lift coefficient converges to different values, depending on the ratio of the free-vortex segment length to the panel length. An optimum lengthscale ratio is recommended for engineering use.

The local details of the solution, such as the load distribution, the shape of the wake, and the induced crossflow velocities have a strong dependence on the wing paneling method and vortex model. Thus, the solution is not unique in this respect. This nonuniqueness would not affect users who require only the aerodynamic coefficients of a single lifting surface. However, users who need the local details of the flow field or ones who use the method to compute interactions between several lifting surfaces and/or bodies, where the correct wake geometry is essental, should be aware of the Iimitations of the VLM and should ensure that the vortex model and paneling they use are adequate for the problem.

\section{References}

${ }^{1}$ Falkner, V. M., "The Calculation of Aerodynamic Loadings on Surfaces of Any Shape," British Aeronaut1ca1 Research Counc11, London, RM 1910, 1943.

${ }^{2}$ Falkner, V. M., "The Solution of Lifting Plane Problems by Vortex Lattice Theory," British Aeronautical Research Counct1, London, RM 2591, 1947.

${ }^{3}$ Falkner, V. M. , "Calculated Loadings Due to Incidence of a Number of Straight and Swept-Back Wings," British Aeronautical Research Council, London, RM 2596, 1948.

${ }^{4}$ Young, J. and Harper, C. W., "Theoretical Symmetric Span Loading at Subsonic Speeds for Wings Having Arbitrary Planforms," NACA TR-921, 1948.

${ }^{5}$ Margason, R. J. and Lamar, J. E., "Vortex Lattice Fortran Program for Estimating Subsonic Aerodynamic Characteristics of Complex Planforms," NASA TN D-6142, Feb. 1971.

${ }^{6}$ Hunt, B., "The Mathematical Basis and Numerical Principles of the Boundary Integral Method for Incompressible Potentlal Flow over 3-D Aerodynamic Conf1gurations," Numerical Methods in Applied Fluid Dynamics, Academic Press, London, 1980, pp. 49-135.

${ }^{7}$ Rehbach, C., "Étude Numérıque de 1 'Influence de la Forme de l'Extrémité d'Une Aile Sur l'Enroulement de la Nappe Tourb1llonna1re," Recherche Aerospacialle, Vol. 1971(145), Nov.-Dec., 1971, pp. 367-368.

${ }^{8}$ Rom, J. and Zorea, C., "The Calculation of the Lift Distribution and the Near Vortex Wake Behind High and Low Aspect Ratio Wings in Subsonic Flow," Technion-Israel Institute of Technology, Hatfa, Israel, TAE-168, Jan. 1973.

${ }^{9}$ Hedman, S. G., "Computation of Vortex Models for Wings at High Angle of Attack in Incompressible Flow," Aeronautical Research Institute of Sweden, Bromma, Sweeden, FFA AU-653, Feb. 1973.

10 Rehbach, C., "Calcul d'Écoulements Autour d'Alles Sans Epaisseur Avec Nappes Tourbillonnaires Évolutives," Recherche Aerospactalle,

Vol, 1973(153), Mar.-Apr. 1973, pp, 53-61.

${ }^{11}$ Maskew, B., "The Calculation of Potential Flow Aerodynamic Characteristics of Combined Lifting Surfaces with Relaxed Wakes," Hawker Siddeley Aviation, Note YAD-3192, Sept. 1973.

12 Rehbach, C., "Étude Numérlque de Nappes Tourbillonnaires Issues d'Une Ligne de Décollement Près du Bord d'Attaque," Recherche Aerospactalle, Vo1. 1973(153), Nov.-Dec. 1973, Pp. 325-330. 
${ }^{13}$ Mook, D.T. and Maddox, S.A., "Extension of a Vortex-Lattice Method to Include the Effects of Leading-Edge Separation," Journal of Alrcraft, Vo1.11, Feb. 1974, pp. 127-128.

${ }^{14}$ Rom, J., Zorea, C., and Gordon, R., "On the Calculation of Nonlinear Aerodynamic Characteristics and the Near Vortex Wake," ICAS Paper 74-27, Aug. 1974.

${ }^{15}$ Kand11, O. A., Mook, D. T., and Nayfeh, A. H., "Nonlinear Prediction of the Aerodynamic Loads on iffting Surfaces," Journal of Aircraft, Vol. 13, Jan. 1976, pp. 22-28.

${ }^{16}$ Kand11, O. A., Mook, D. T., and Nayfeh, A. H., "A Numerical Technique for Computing Subsonic Flow Past Three-Dimensiona1 Canard-Wing Conf1gurations wtth Edge Separations," AIAA Paper 77-1, Jan. 1977.

${ }^{17}$ Kand11, O. A., Atta, E. H., and Nayfeh, A. H., "Three Dimensional Steady and Unsteady Asymetric Flow Past Wings of Arbitrary Planforms," AGARD CP-227, Sept. 1977.

${ }^{18}$ Rom, J., Almosnino, D., and Zorea, C., "Calculation of the Nonlinear Aerodynamic Coefficient of Wings of Varlous Shapes and Their Wakes, Including Canard Conflgurations," Proceedings of the 11th ICAS Congress, Vol. 1, Sept. 1978, pp. 333-344.

${ }^{19} \mathrm{Almosnino,"D.} \mathrm{and} \mathrm{Rom,} \mathrm{J.,} \mathrm{"Calculation} \mathrm{of}$ Symmetric Vortex Separation Affecting Subsonic Bodies at H1gh Inctdence," AIAA Journal, Vo1. 21, Mar. 1983, 'pp. 398-406.

${ }^{20}$ Almosnino, D., "High Angle-of-Attack Calculations of the Subsonic Vortex Flow on Slender Bodies," AIAA Paper 83-0035, Jan. 1983.
${ }^{21}$ Rusak, Z., Wasserstrom, E., and Seginer, A., "Numerical Calculation of Nonlinear Aerodynamics of Wing-Body Configurations," AIAA Journal,

(Paper J13442), to be published June 1983.

${ }^{22}$ Rusak, Z., "Numerical Calculation of WingBody Conflgurations," Technion-Israel Institute of Technology, Haffa, Israel, M.Sc. Thesis, Jan. 1982.

${ }^{23}$ Hess, J. L. and Smith, A. M. O., "Calculation of Potent1al Flow About Arbitrary Bodfes," Progress In Aeronautical Sciences, Vo1. 8, Pergamon Press, New York, 1967.

${ }^{24}$ Woodward, F. A., "USSAERO Computer Program Development, Versions B and C," NASA CR-3227, Apr. 1980.

${ }^{25}$ Almosnino, D., "A Method for the Calculation of the Longitudinal Aerodynamlc Coeffictents of Bodies in Subsontc Flow and at High Angles of Attack," Technion-Israel Institute of Technology, D.Sc. Thesis, June 1981 .

${ }^{26}$ Wentz, W. H., Jr., "Effects of Leading-Edge Camber on Low-Speed Characteristics of Slender Delta Wings," NASA CR-2002, Oct. 1972.

${ }^{27}$ Sforza, P. M., Stati, W., Pazienza, J., and Smorto, M., "Flow Measurements in Leading Edge Vort1ces," AIAA Paper 77-11, Jan. 1977.

${ }^{28}$ Gordon, R. and Rom, J., "Calculation of Aerodynamic Characteristics of Wings with Thickness and Camber by a New Method Based on the Modified Vortex Lattice Method," Technion-Israel Institute of Technology, Israe1, TAE Report 493, July 1982.
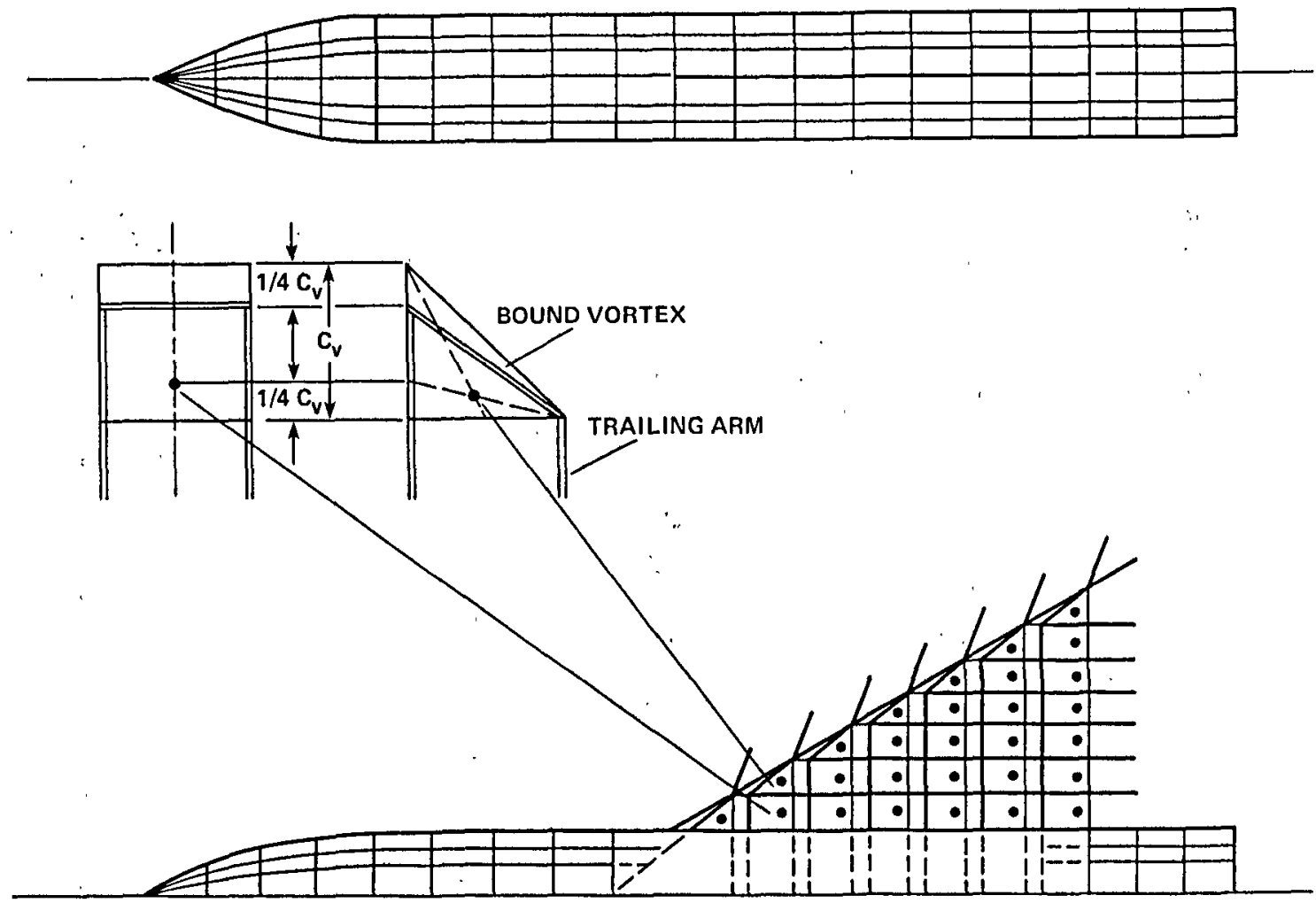

Fig. 1 Schematic division of a wing-body configuration into source and vortex panels. 


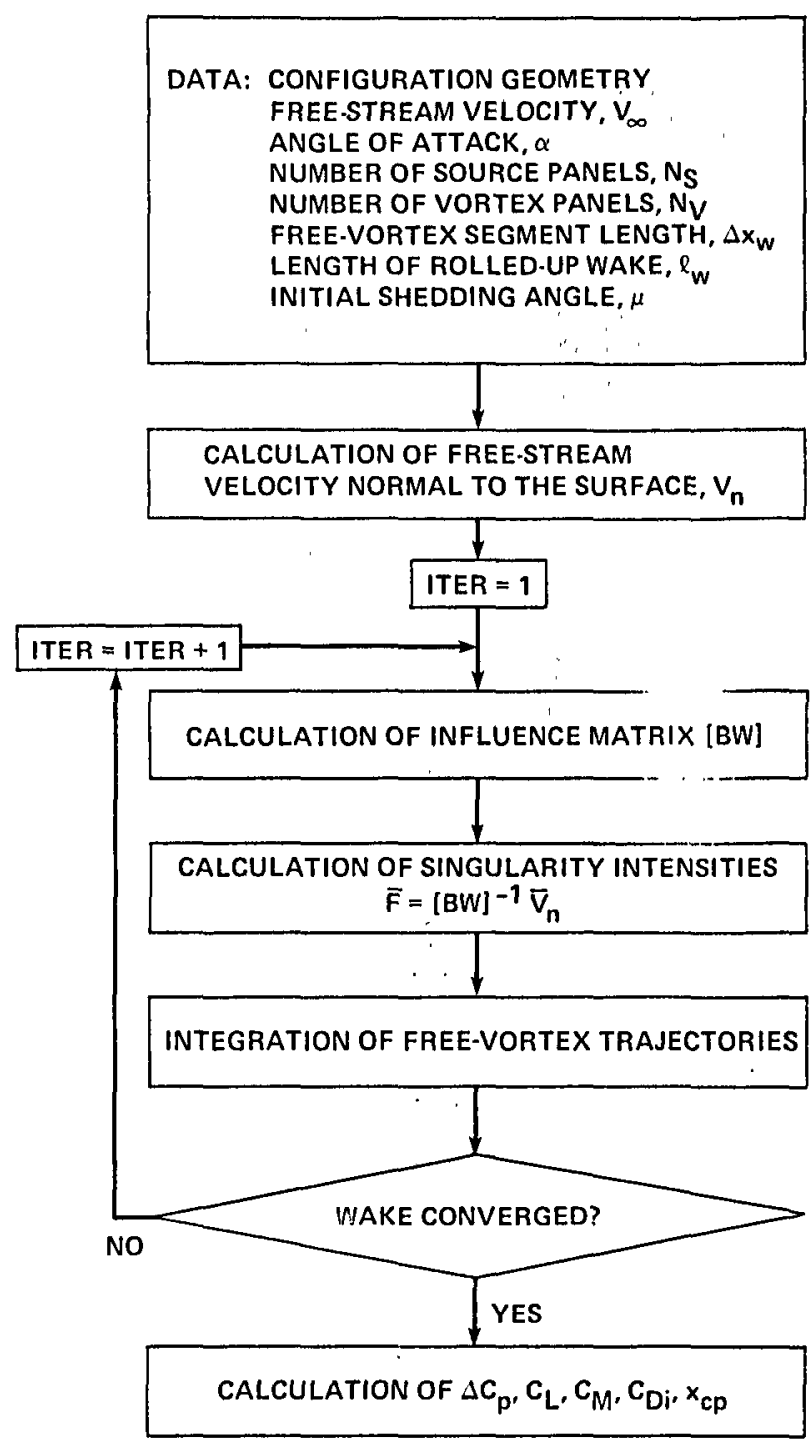

Fig. 2 Flow chart of the iterative computation procedure.

SOURCE-PANEL METHOD:
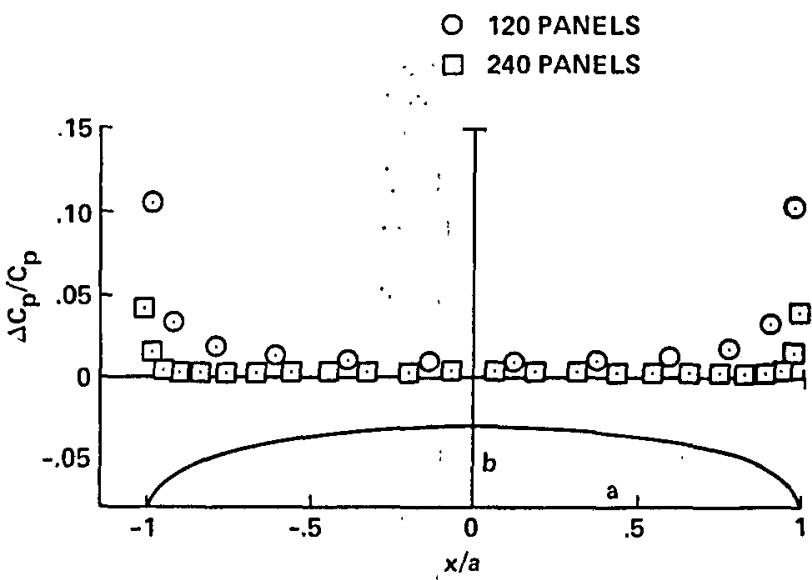

Fig. 3 The pressure distribution on an ellipsold differences between the numerical and analytical solutions.
SOURCE-PANEL METHOD:

WOODWARD PROGRAM (REF. 24)

O PRESENT PROGRAM

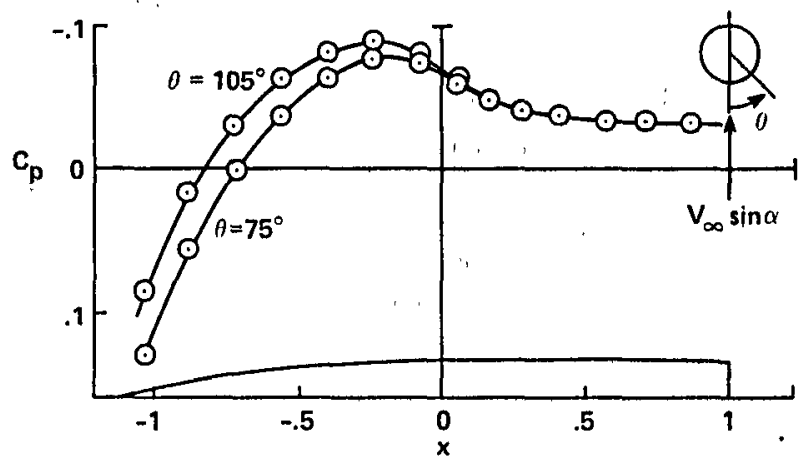

Fig. 4 Pressure distribution on an ogive-cylinder at $\alpha=6^{\circ}$.

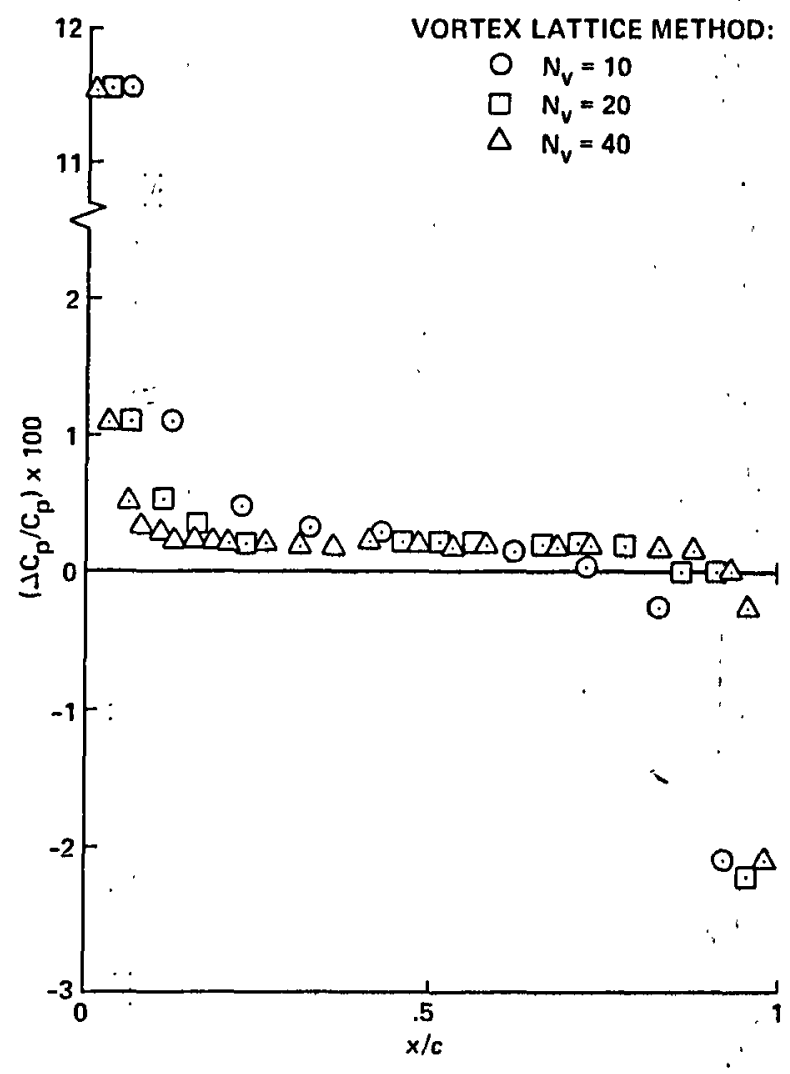

Fig. 5 Relative error in the chordwise load distribution on a two-dimensional flat-plate alrfoil section, $a=4^{\circ}$.

$\because$ 


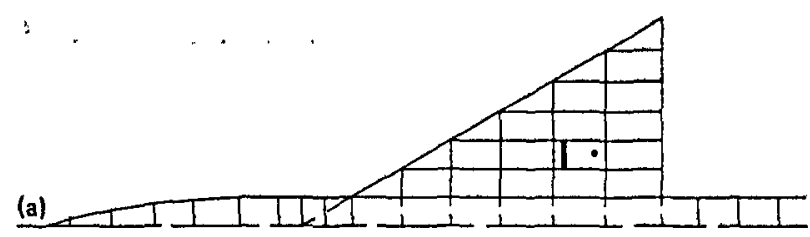

(b)

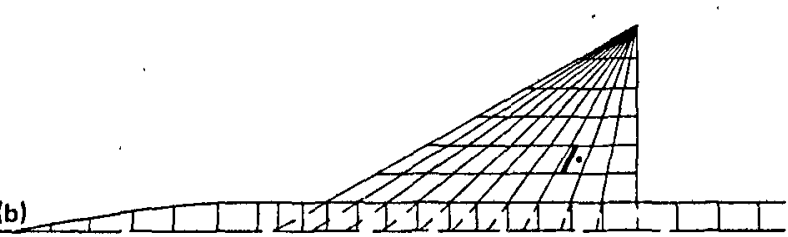

(c)

F1g. 6 Paneling of a wing-body configuration by several linear panel methods.

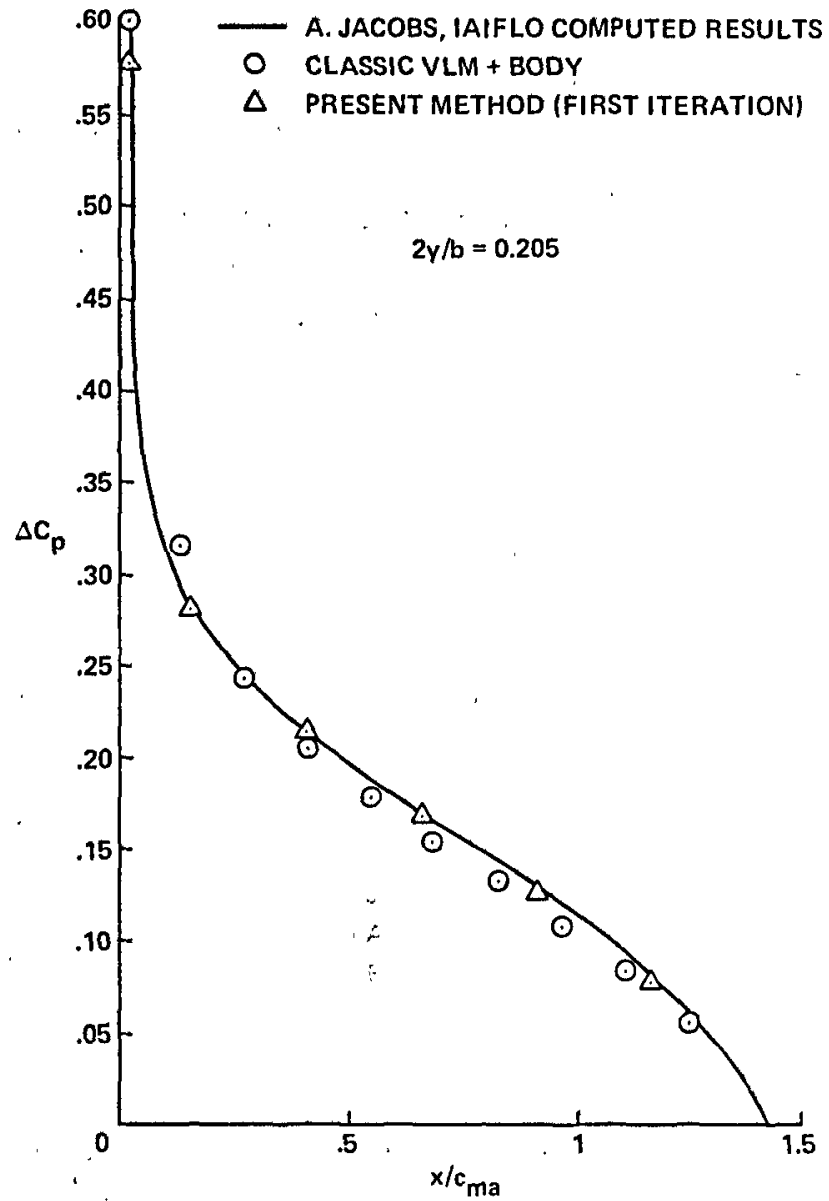

Fig. 7 Chordwise load distribution on the wing of F1g. 6 at $20.5 \%$ span and $\alpha=6^{\circ}$. 

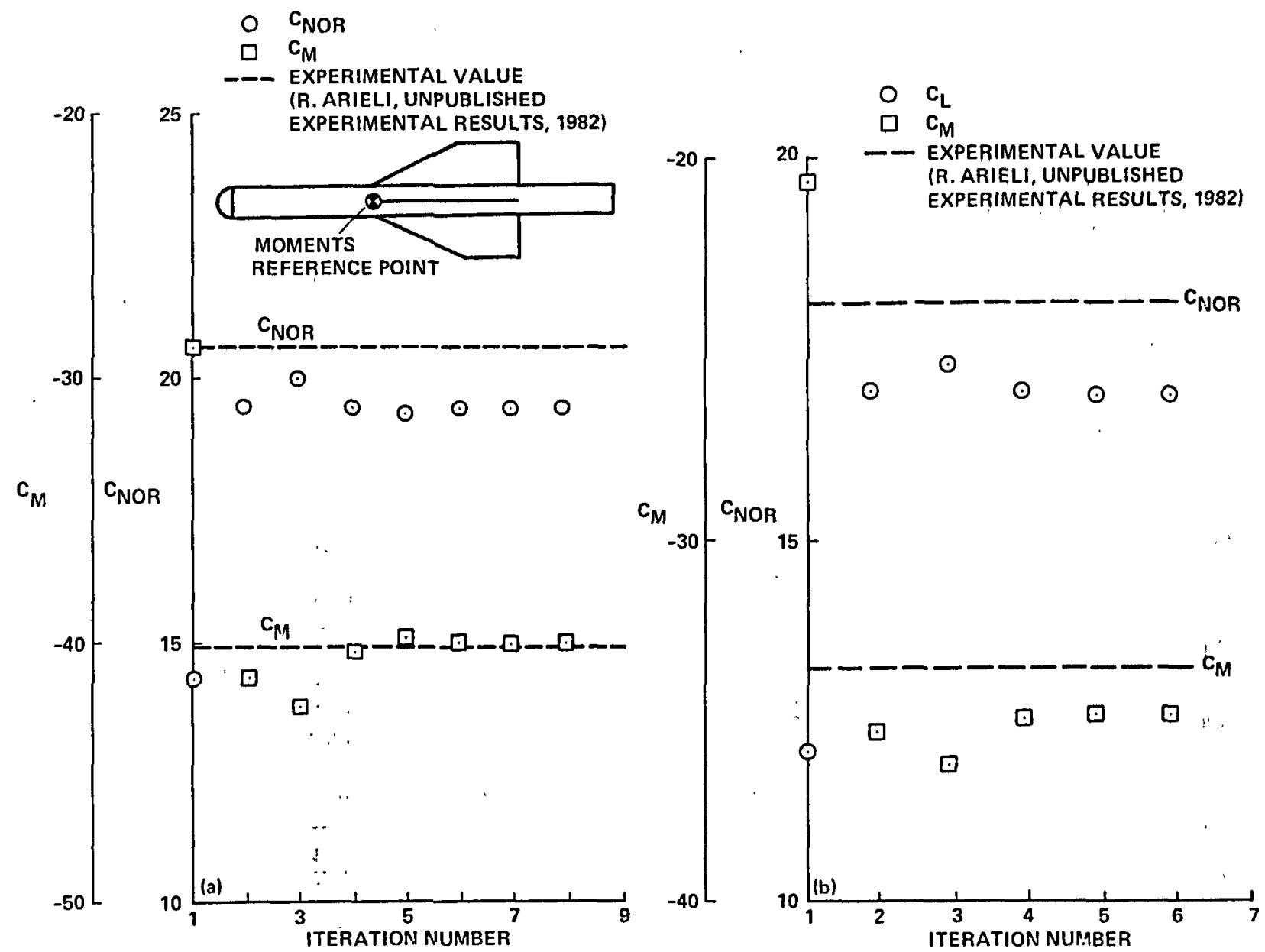

Fig. 8 Typical solution - convergence process. a) Wings in a "plus" (+) position. b) Wings in an " $x$ " position. 

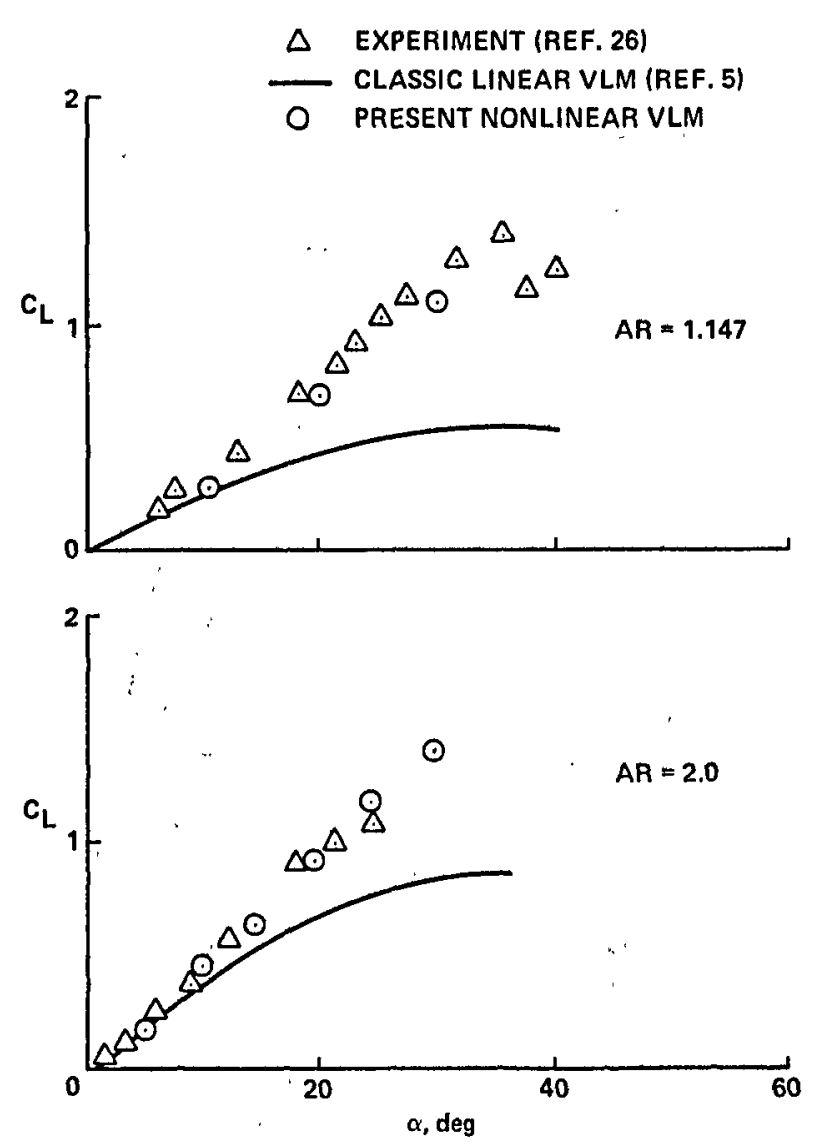

F1g. 9 Lift coeficient prediction by vartous methods.

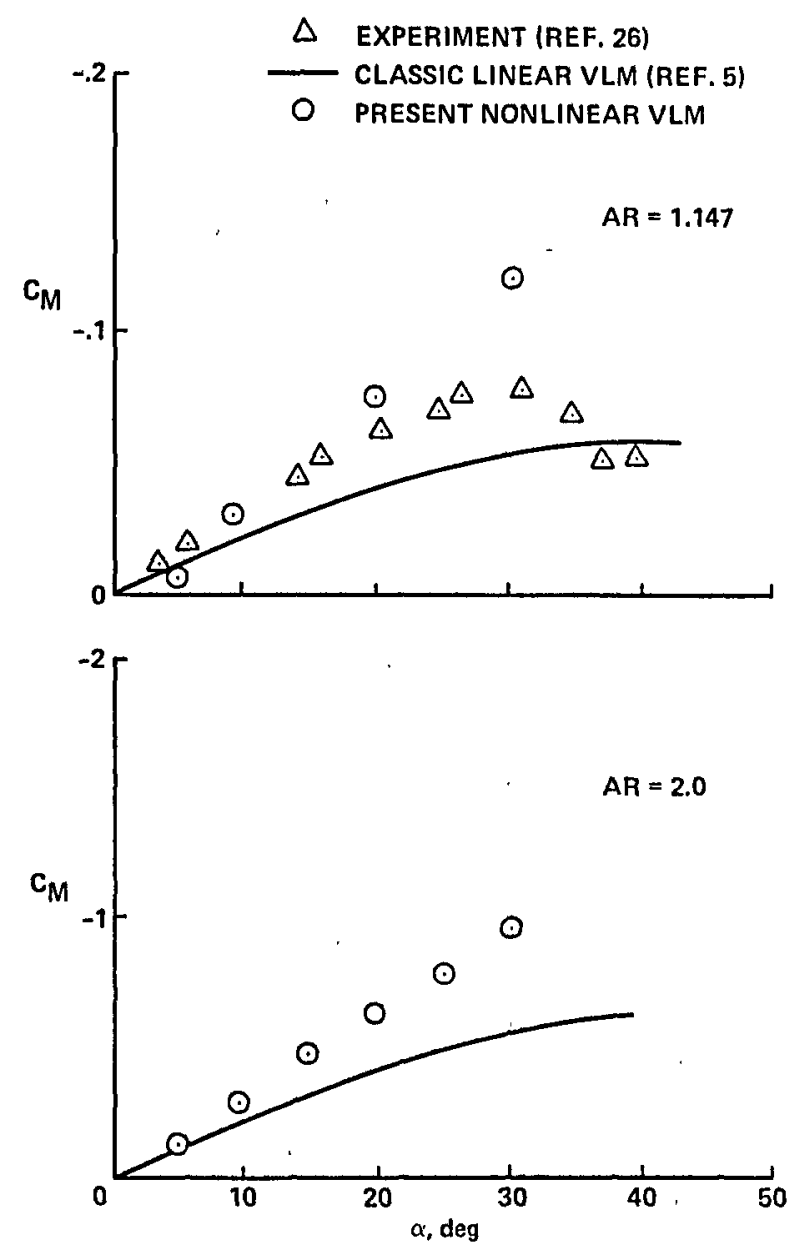

F1g. 10 Pitching-moment coefficient prediction by various methods. 


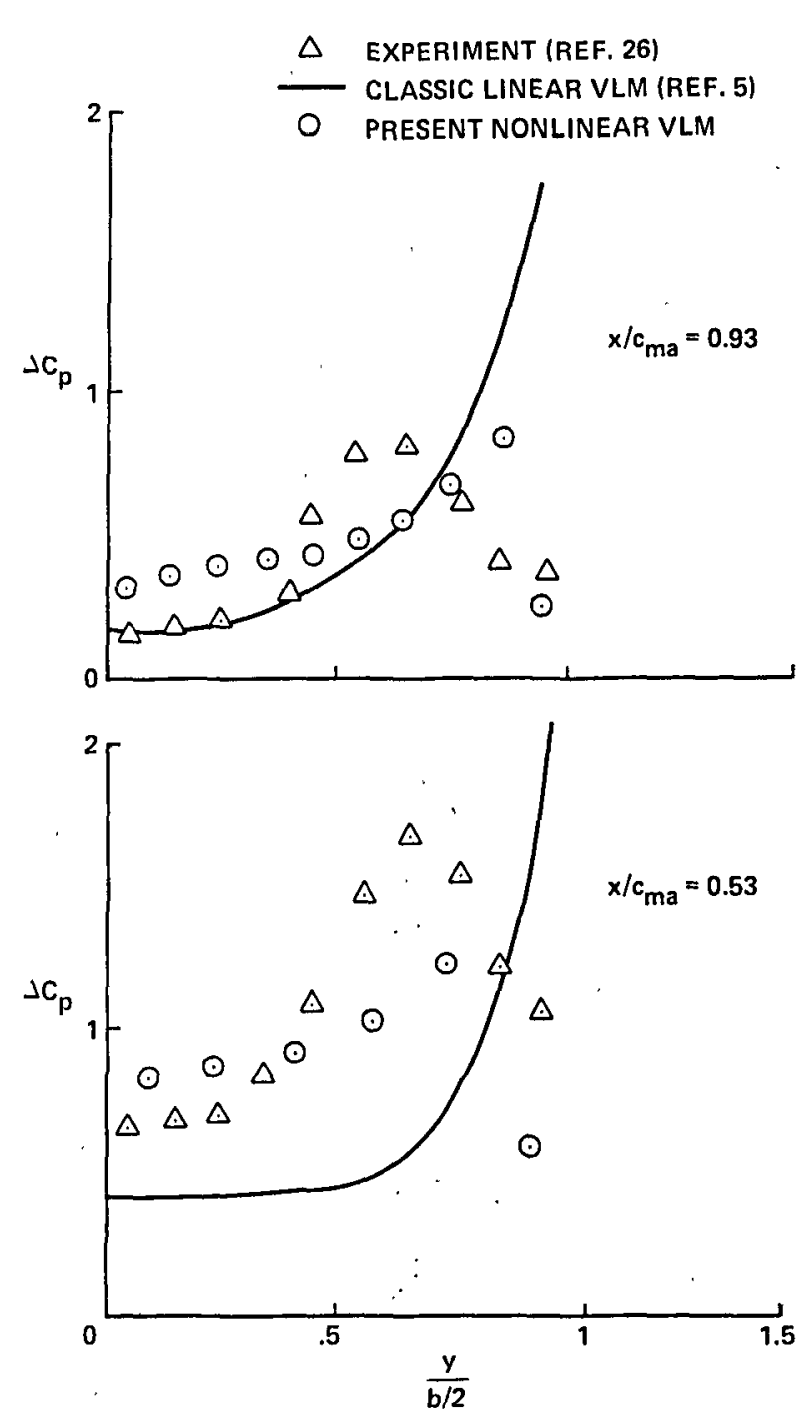

F1g. 11 Prediction of load distributions by various methods.

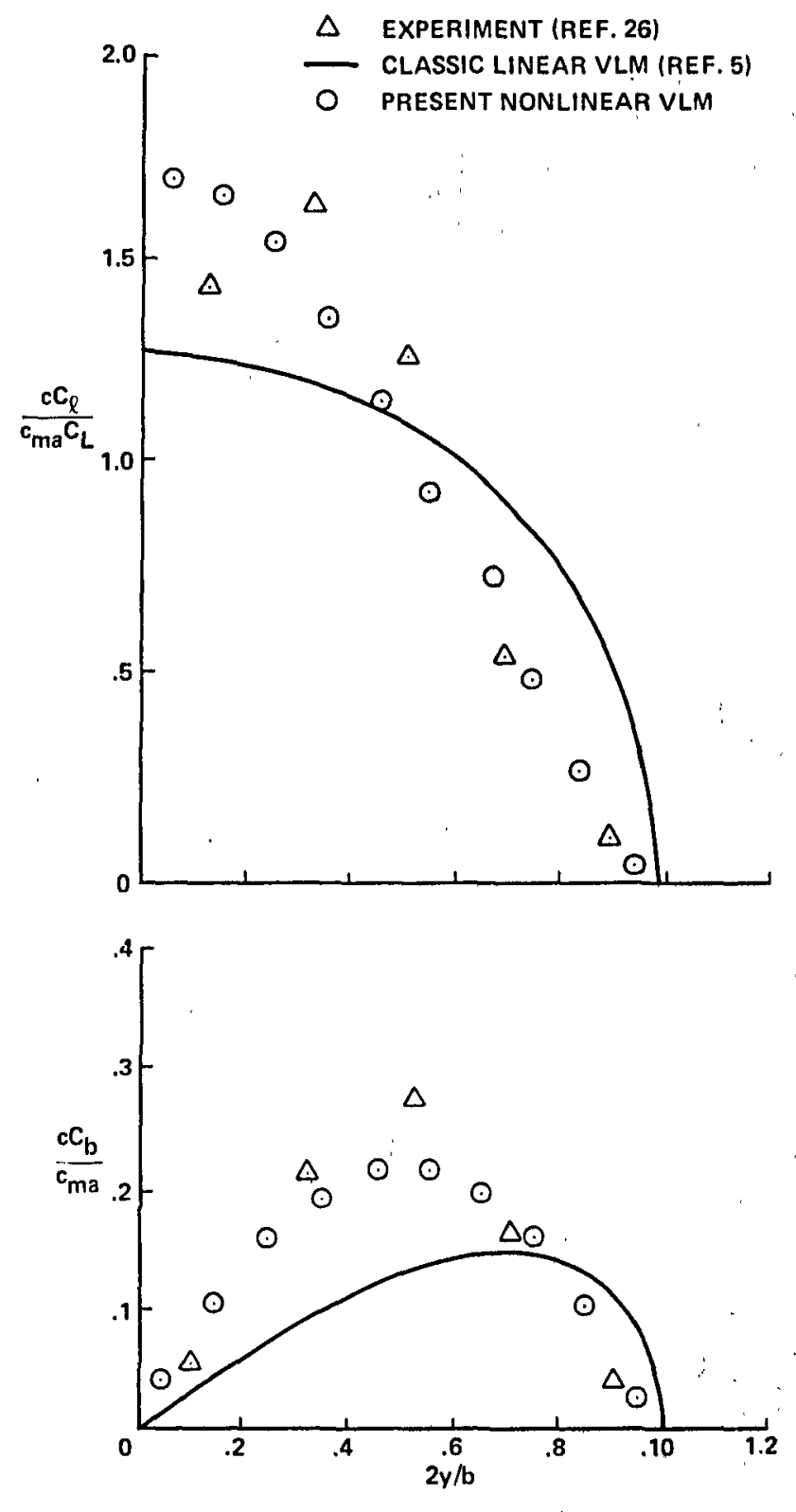

F1g. 12 Spanwise distribution of section 1 ift coefficient and span bending moment. 
$=\underset{0}{\stackrel{2}{L}} \frac{V_{y z}}{V_{\infty}}$ SCALING

DELTA AR $=1.0, \alpha=20^{\circ}$

VORTEX LOCATION

O) AND INTENSITY CALCULATED CROSS-FLOW

$\rightarrow$ VELOCITY VECTOR $\left(V_{y z}\right)$

O CENTER OF ROTATION

CÁLCULATED CENTER OF

(2) GRAVITY OF VORTICITY

+ CORE LOCATION (REF. 27)

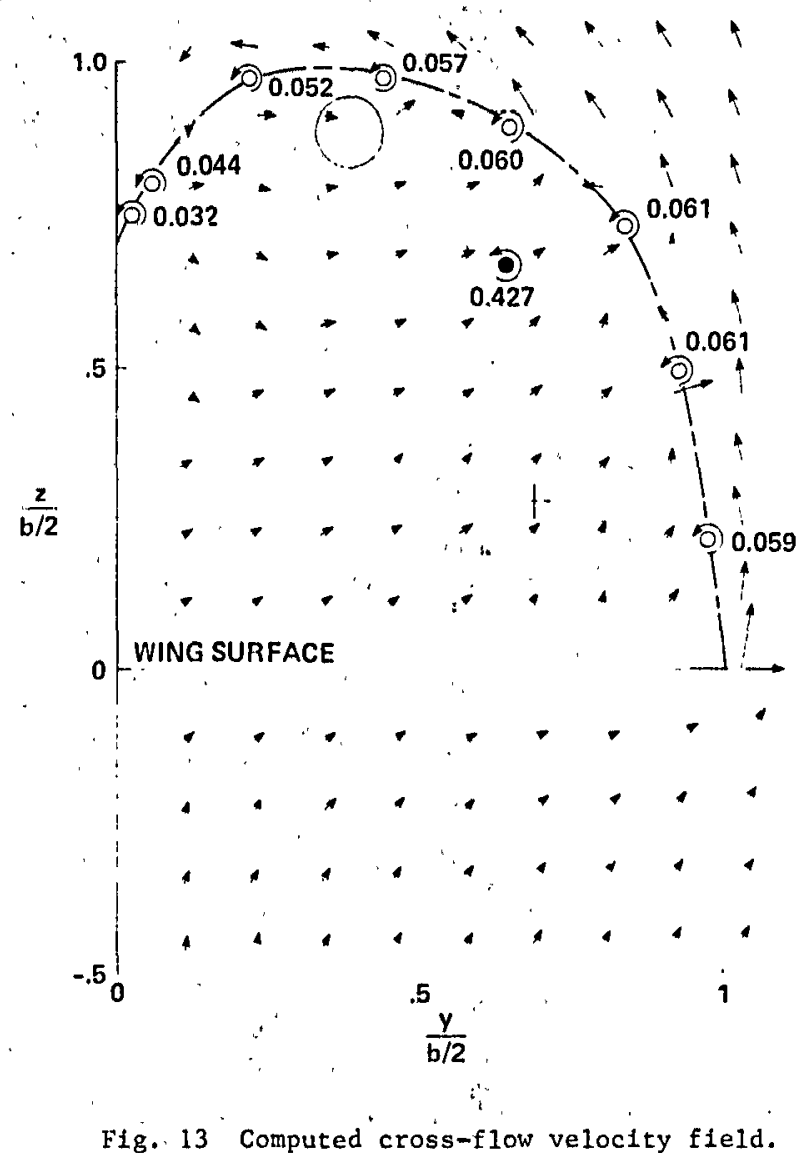

Fig. 13 Computed cross-flow velocity field. 


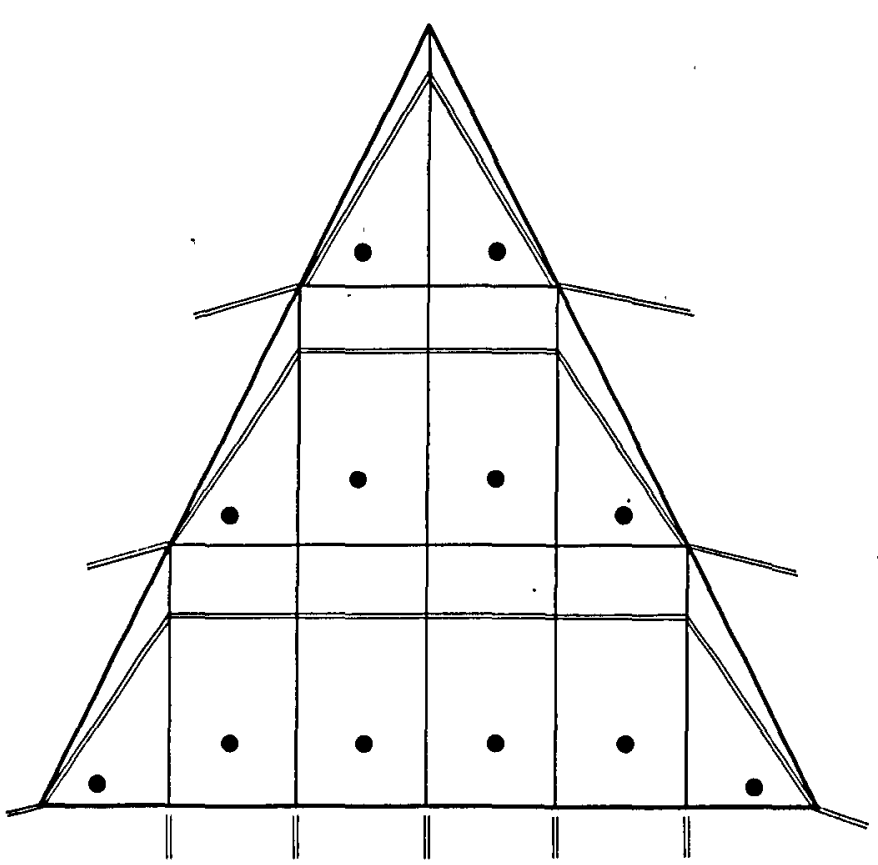

(a) PRESENT ROM-ZOREA ${ }^{8}$ PANELLING METHOD

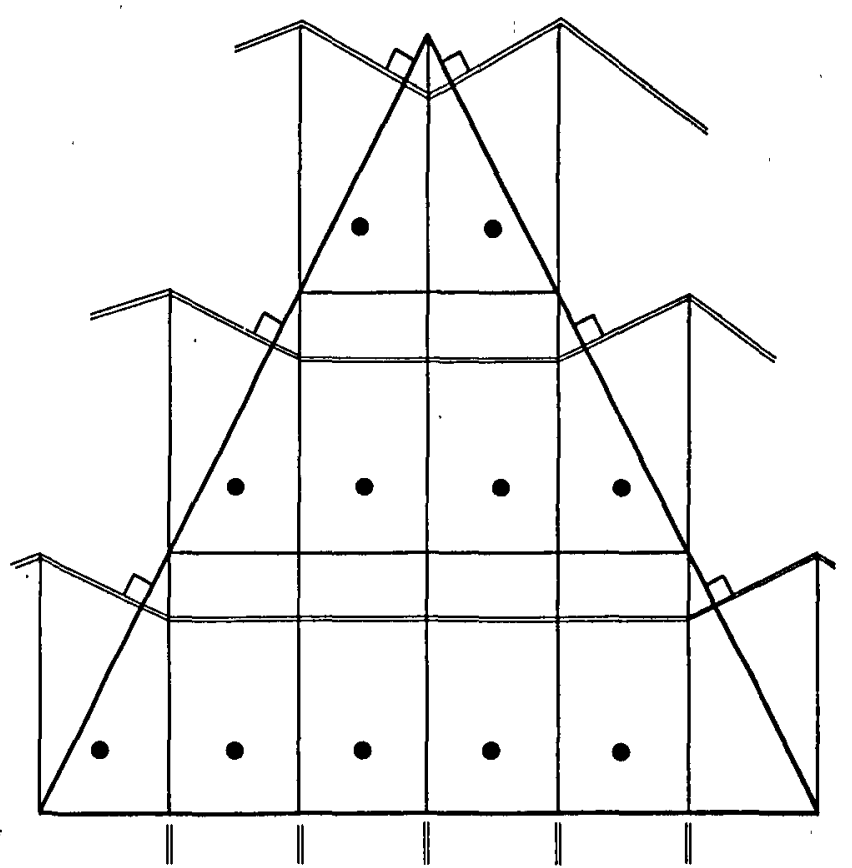

(b) PANELLING METHOD OF REF. 15

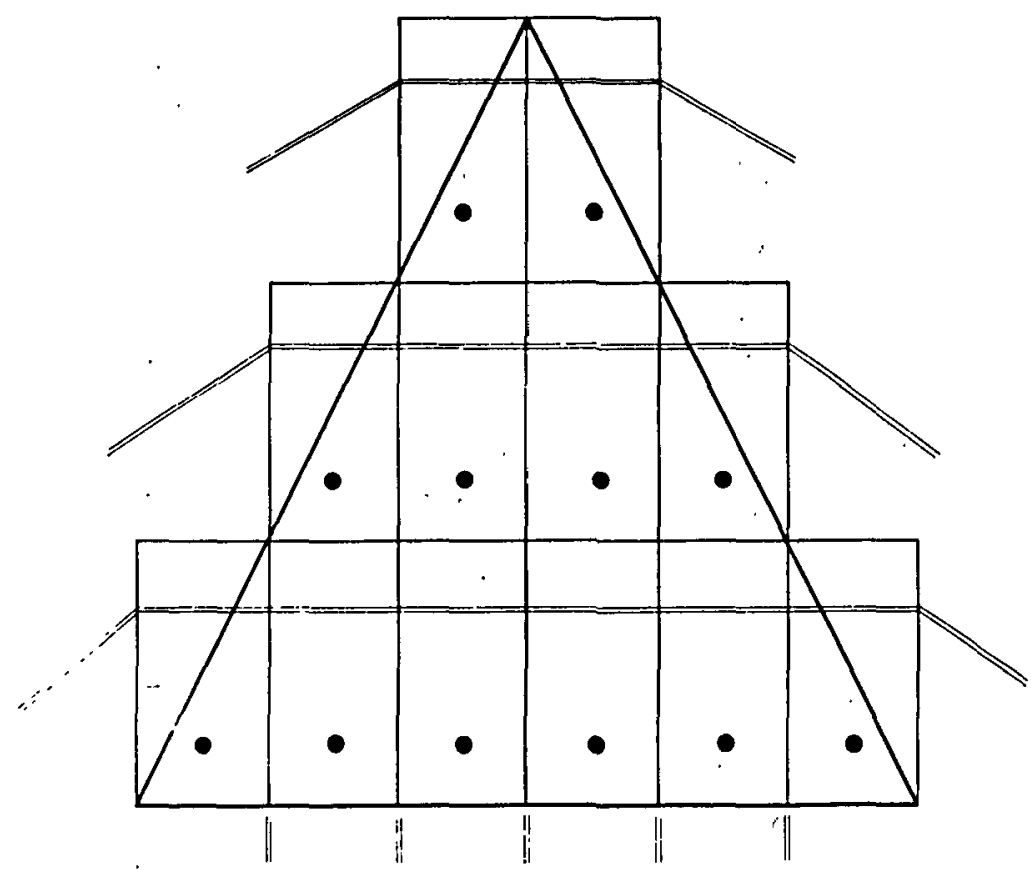

(c) GORDON-ROM ${ }^{28}$ PANELLING METHOD

Fig. 14 Comparison of nonlinear paneling methods. 


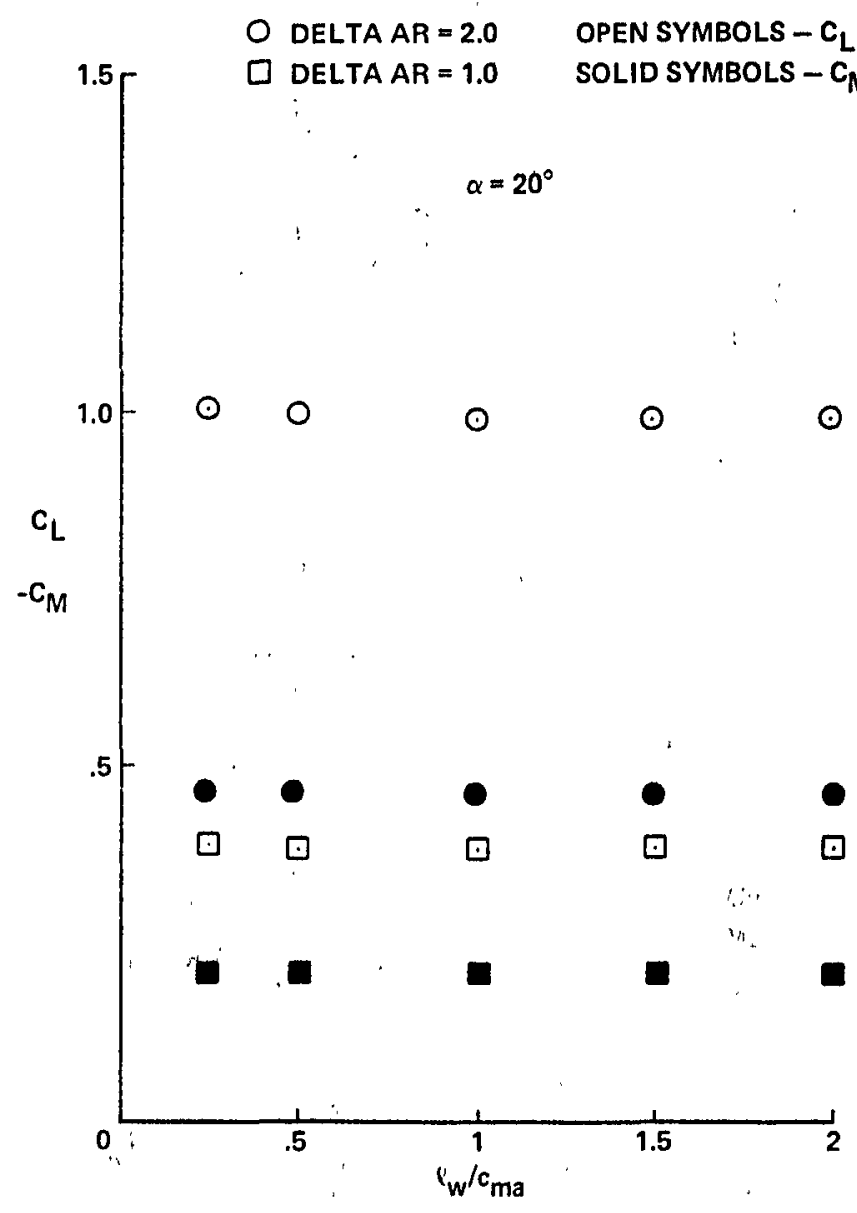

Fig. 15 Effects of rolled-up wake length on the converged solution.

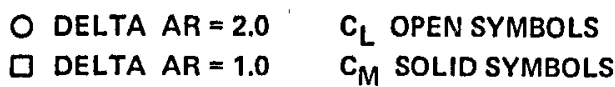

$$
\alpha^{\prime}=20^{\circ}
$$

$\odot$

$\odot$

$\odot$

$\odot$
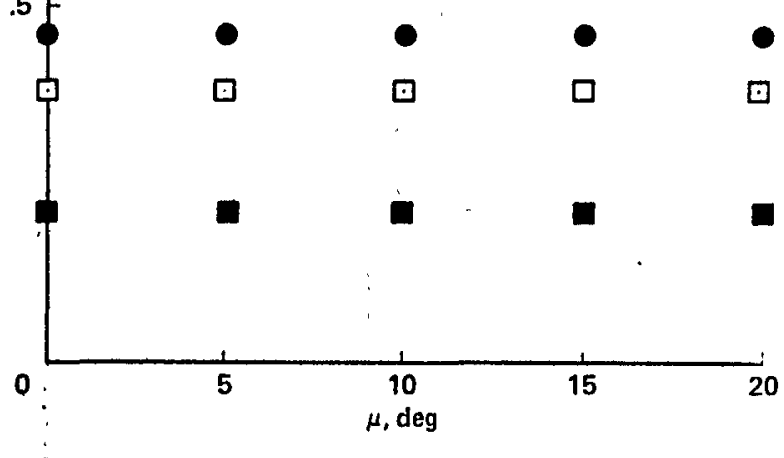

Fig. 16 Effects of the infial shedding angle on the converged aerodynamic coefficlents. 


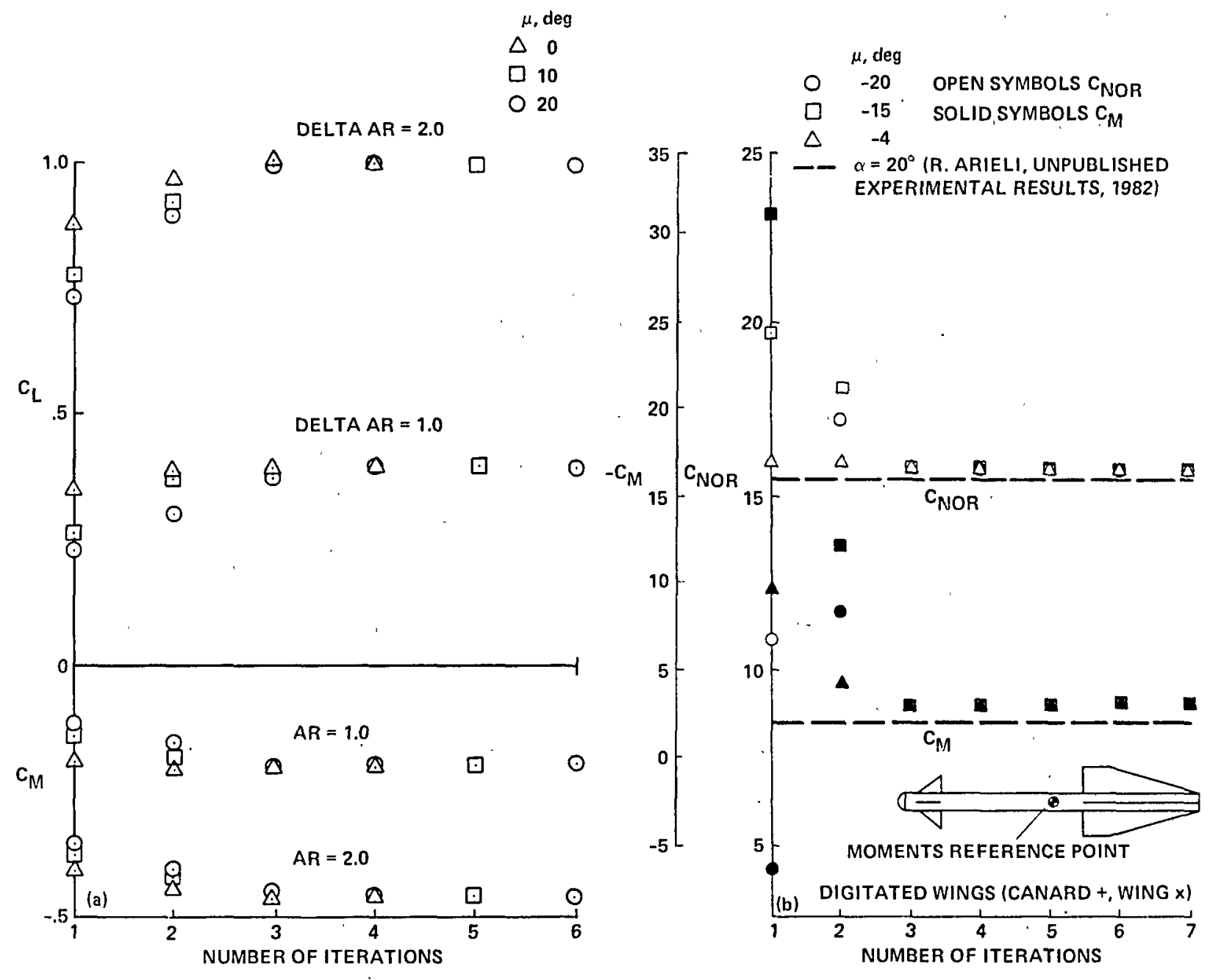

Fig. 17 Effects of the initial shedding angle on the convergence rate. a) Shedding angles between the free stream and the wing plane. b) Wake deflected far above the wing. 


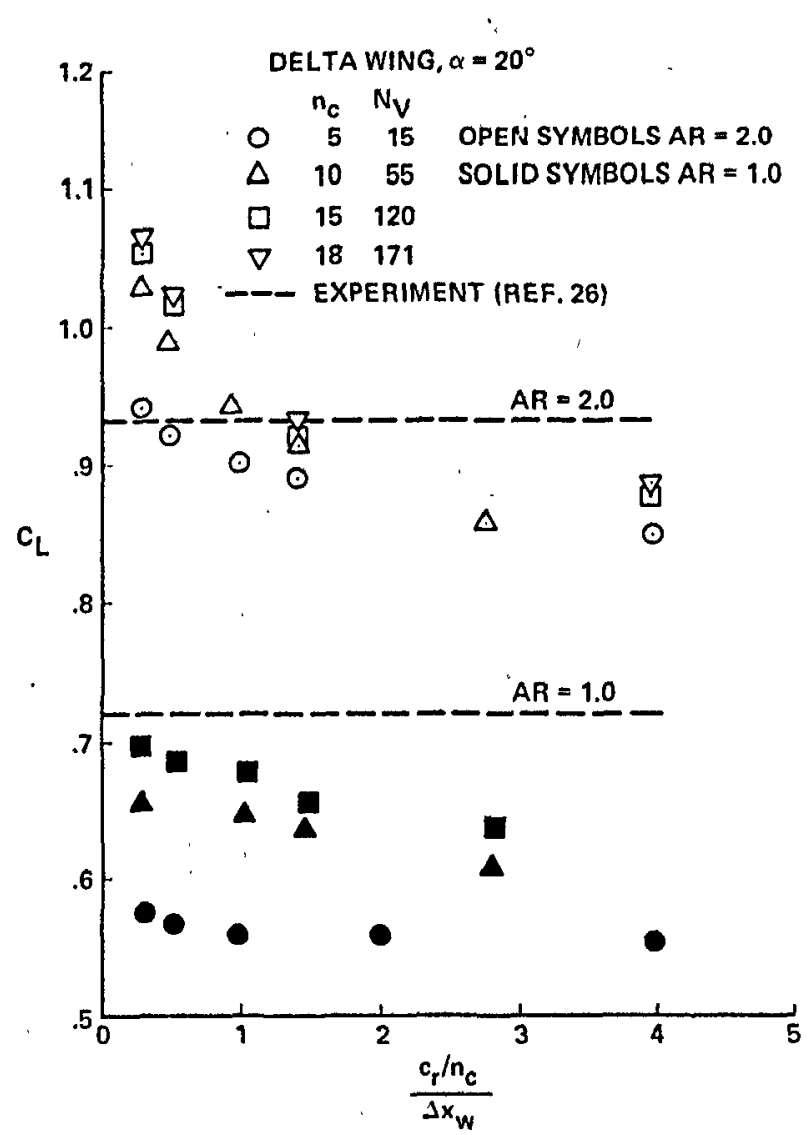

F1g. 18 Convergence of the lift coefficient with the reduction in the free-vortex segment length.

DELTA WING, $\alpha=20^{\circ}$

AR
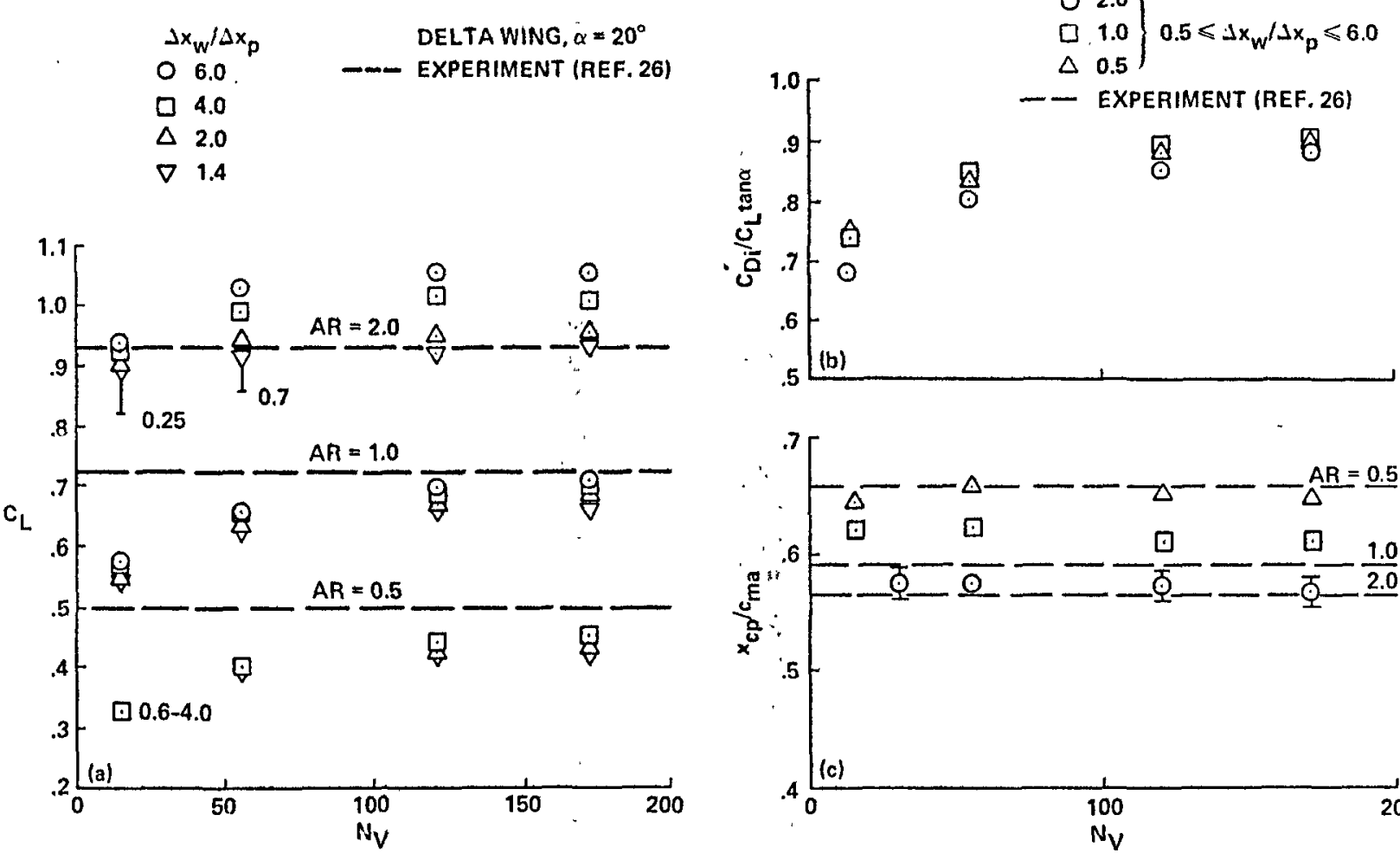

O 2.0

․ $1.0 \quad 0.5 \leqslant \Delta x_{w} / \Delta x_{p} \leqslant 6.0$

$\triangle 0.5$

RIMENT (REF, 26

$\triangle 2.0$

$\nabla \mathbf{1 . 4}$

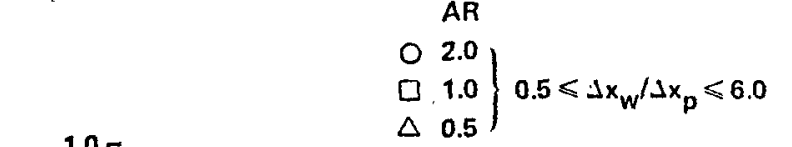




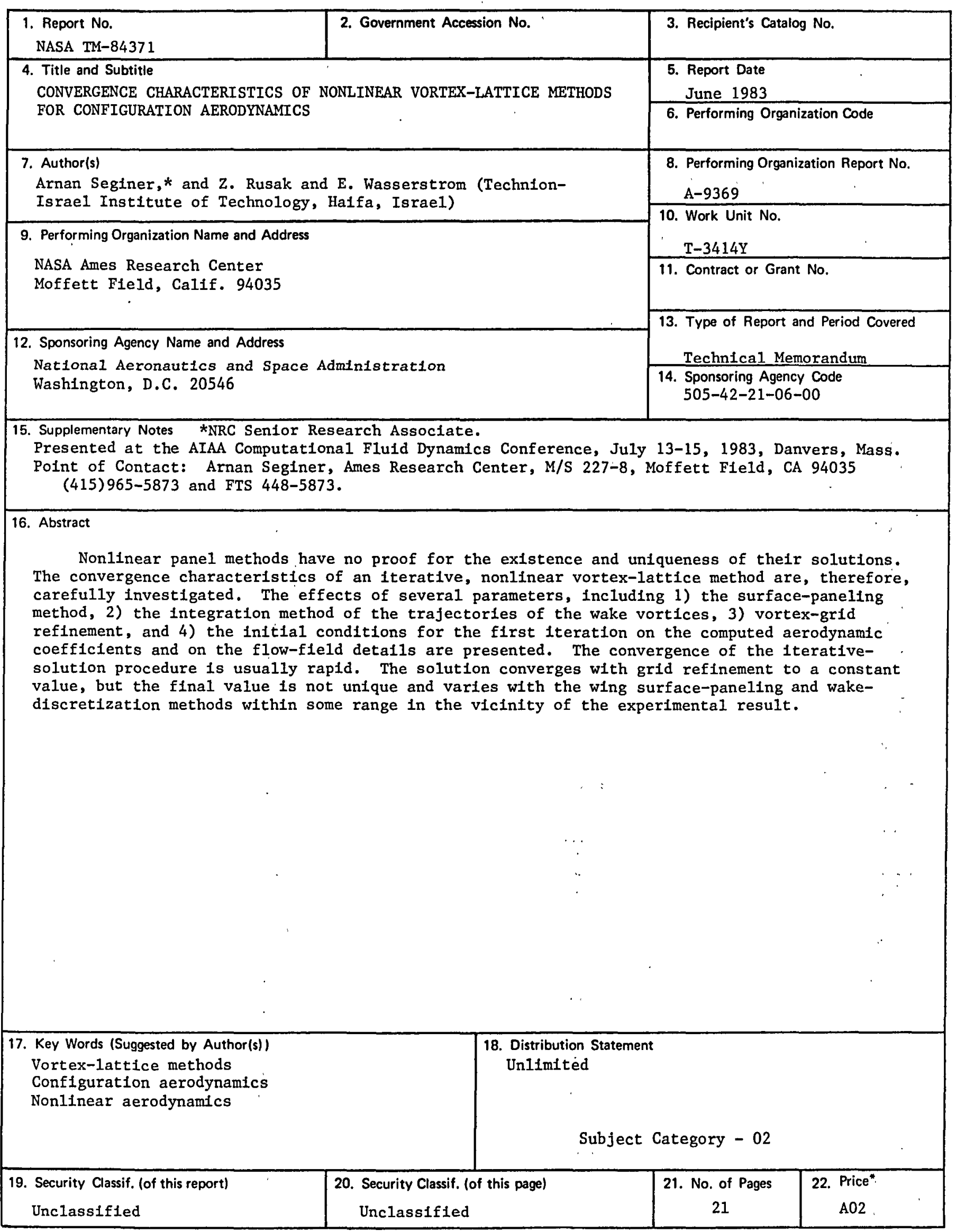

